\title{
A simplified thermoregulation model of the human body in warm conditions
}

\section{Article}

\section{Accepted Version}

Creative Commons: Attribution-Noncommercial-No Derivative Works 4.0

Li, B., Yang, Y., Yao, R., Liu, H. and Li, Y. (2017) A simplified thermoregulation model of the human body in warm conditions. Applied Ergonomics, 59 (A). pp. 387-400. ISSN 0003-6870 doi: https://doi.org/10.1016/j.apergo.2016.09.010 Available at https://centaur.reading.ac.uk/68981/

It is advisable to refer to the publisher's version if you intend to cite from the work. See Guidance on citing.

Published version at: http://dx.doi.org/10.1016/j.apergo.2016.09.010

To link to this article DOI: http://dx.doi.org/10.1016/j.apergo.2016.09.010

Publisher: Elsevier

All outputs in CentAUR are protected by Intellectual Property Rights law, including copyright law. Copyright and IPR is retained by the creators or other copyright holders. Terms and conditions for use of this material are defined in the End User Agreement.

\section{www.reading.ac.uk/centaur}

\section{CentAUR}

Central Archive at the University of Reading

Reading's research outputs online 


\section{A Simplified Thermoregulation Model of the Human Body in Warm Conditions}

Baizan Li ${ }^{\text {a,b }}$; Yu Yang a,b,c; Runming Yao ${ }^{\text {a,b,c * }}$; Hong Liu ${ }^{\text {a,b }}$; Yongqiang Li ${ }^{\text {a,b,c }}$

a Joint International Laboratory of Green Buildings and Built Environments, Ministry of Education; Chongqing University, Chongqing, China;

${ }^{\mathrm{b}}$ National Centre for International Research of Low-carbon and Green Buildings, Ministry of Science and Technology; Chongqing University, Chongqing, China;

${ }^{c}$ School of the Built Environment, University of Reading, UK

Highlights

A new simplified thermoregulation model of the human body;

Laboratory experimental data used for model verification;

Prediction of skin temperature in transient thermal processes

Nomenclature

A body surface area $\left(\mathrm{m}^{2}\right)$

$A_{r} \quad$ effective radiation area of body $\left(\mathrm{m}^{2}\right)$

$\mathrm{BF}_{\mathrm{i}} \quad$ total blood flow of layer $\mathrm{i}(1 / \mathrm{h})$

c $\quad$ specific heat $\left[\mathrm{J} /\left(\mathrm{kg} \bullet{ }^{\circ} \mathrm{C}\right)\right]$

C convective heat losses $\left(\mathrm{W} / \mathrm{m}^{2}\right)$
RH Relative humidity (\%)

$\mathrm{r}_{\mathrm{s}, \mathrm{i}} \quad$ external radius of layer I (m)

ST vasoconstriction signal $(1 / \mathrm{h})$

$\mathrm{t} \quad$ time $(\mathrm{s})$

$\mathrm{T}^{\prime} \quad$ temperature change rate $\left({ }^{\circ} \mathrm{C} / \mathrm{s}\right)$

$\mathrm{T}_{\mathrm{a}} \quad$ mean air temperature $\left({ }^{\circ} \mathrm{C}\right)$

$\mathrm{T}_{\mathrm{b}}$ temperature of blood $\left({ }^{\circ} \mathrm{C}\right)$ 


\begin{tabular}{|c|c|c|c|}
\hline $\mathrm{C}_{\mathrm{res}}$ & $\begin{array}{l}\text { respiratory convective heat flow per } \\
\text { body surface area }\left(\mathrm{W} / \mathrm{m}^{2}\right)\end{array}$ & $\mathrm{T}_{\mathrm{cl}}$ & $\begin{array}{l}\text { mean temperature of the outer } \\
\text { surface of the clothed body }\left({ }^{\circ} \mathrm{C}\right)\end{array}$ \\
\hline DL & vasodilation signal (1/h) & $\mathrm{T}_{\mathrm{i}}$ & temperature of tissue $\left({ }^{\circ} \mathrm{C}\right)$ \\
\hline $\mathrm{E}_{\text {diff }}$ & $\begin{array}{l}\text { diffusion evaporative heat loss } \\
\text { per body surface area }\left(\mathrm{W} / \mathrm{m}^{2}\right) \\
\text { evaporative heat loss from }\end{array}$ & $\mathrm{T}_{\mathrm{r}}$ & mean radiant temperature $\left({ }^{\circ} \mathrm{C}\right)$ \\
\hline $\mathrm{E}_{\mathrm{res}}$ & $\begin{array}{l}\text { respiration per body surface area } \\
\left(\mathrm{W} / \mathrm{m}^{2}\right)\end{array}$ & $\mathrm{T}_{\mathrm{set}, \mathrm{c}}$ & core temperature set point $\left({ }^{\circ} \mathrm{C}\right)$ \\
\hline $\operatorname{Err}_{\mathrm{c}}$ & input signals of core layer $\left({ }^{\circ} \mathrm{C}\right)$ & $\mathrm{T}_{\mathrm{set}, \mathrm{s}}$ & skin temperature set point $\left({ }^{\circ} \mathrm{C}\right)$ \\
\hline $\operatorname{Err}_{\mathrm{s}}$ & input signals of skin layer $\left({ }^{\circ} \mathrm{C}\right)$ & $\mathrm{T}_{\mathrm{v}}$ & venous temperature $\left({ }^{\circ} \mathrm{C}\right)$ \\
\hline $\mathrm{E}_{\mathrm{sw}}$ & $\begin{array}{l}\text { evaporative heat loss by sweating } \\
\text { per body surface area }\left(\mathrm{W} / \mathrm{m}^{2}\right)\end{array}$ & $\mathrm{V}_{\mathrm{a}}$ & mean air velocity $(\mathrm{m} / \mathrm{s})$ \\
\hline $\mathrm{f}_{\mathrm{cl}}$ & clothing area factor & $\mathrm{V}_{\mathrm{i}}$ & volume of layer $\mathrm{I}\left(\mathrm{m}^{3}\right)$ \\
\hline $\mathrm{H}$ & height of human body $(\mathrm{cm})$ & $\mathrm{W}$ & weight of human body (kg) \\
\hline $\mathrm{h}_{\mathrm{c}}$ & $\begin{array}{l}\text { convective heat transfer } \\
\text { coefficient }\left(\mathrm{W} / \mathrm{m}^{2} \cdot{ }^{\circ} \mathrm{C}\right)\end{array}$ & $\alpha_{\mathrm{m}, \mathrm{i}}$ & proportion of layer i in weight (\%) \\
\hline $\mathrm{I}_{\mathrm{cl}}$ & $\begin{array}{l}\text { total thermal insulation of } \\
\text { clothing (clo) }\end{array}$ & $\beta$ & counter-current factor \\
\hline $\mathrm{L}$ & length of cylinder (m) & $\varepsilon$ & $\begin{array}{l}\text { average emissivity of clothing or } \\
\text { body surface }\end{array}$ \\
\hline M & total metabolic rate $\left(\mathrm{W} / \mathrm{m}^{2}\right)$ & $\lambda$ & $\begin{array}{l}\text { heat conductivity coefficient } \\
{[\mathrm{W} /(\mathrm{m} \cdot \mathrm{k})]}\end{array}$ \\
\hline $\mathrm{M}_{\mathrm{b}}$ & total basal metabolic rate $\left(\mathrm{W} / \mathrm{m}^{2}\right)$ & $\rho$ & density $\left(\mathrm{kg} / \mathrm{m}^{3}\right)$ \\
\hline $\mathrm{M}_{\mathrm{b}, \mathrm{i}}$ & $\begin{array}{l}\text { heat production by basic } \\
\text { metabolism per cubic metre }\left(\mathrm{W} / \mathrm{m}^{3}\right)\end{array}$ & $\sigma$ & $\begin{array}{l}\text { Stefan-Boltzmann constant[W/ } \\
\left.\left(\mathrm{m}^{2} \cdot \mathrm{K}^{4}\right)\right]\end{array}$ \\
\hline $\mathrm{m}_{\mathrm{cl}}$ & weight of the clothing $(\mathrm{kg})$ & & \\
\hline $\mathrm{M}_{\mathrm{s}, \mathrm{i}}$ & $\begin{array}{l}\text { heat production by shivering per } \\
\text { cubic metre }\left(\mathrm{W} / \mathrm{m}^{3}\right)\end{array}$ & & Subscript \\
\hline $\mathrm{M}_{\mathrm{shi}}$ & shivering heat production $\left(\mathrm{W} / \mathrm{m}^{2}\right)$ & $\mathrm{i}$ & layer number \\
\hline $\mathrm{M}_{\mathrm{w}, \mathrm{i}}$ & $\begin{array}{l}\text { heat production by activity } \\
\text { metabolism per cubic metre }\left(\mathrm{W} / \mathrm{m}^{3}\right)\end{array}$ & 1 & layer of core \\
\hline $\mathrm{P}_{\mathrm{a}}$ & water vapour partial pressure $(\mathrm{Pa})$ & 2 & layer of muscle \\
\hline $\mathrm{Q}_{\mathrm{b}}$ & total blood flow to cylinder $\left(\mathrm{m}^{3}\right)$ & 3 & layer of fat \\
\hline $\mathrm{Q}_{\mathrm{i}}$ & $\begin{array}{l}\text { blood flow per cubic metre of } \\
\text { layer } i\left[\mathrm{~m}^{3} /\left(\mathrm{s} \cdot \mathrm{m}^{3}\right)\right]\end{array}$ & 4 & layer of skin \\
\hline $\mathrm{r}$ & radius of cylinder (m) & $\mathrm{b}$ & central blood node \\
\hline $\mathrm{R}_{\mathrm{d}}$ & $\begin{array}{l}\text { radiative heat losses }\left(\mathrm{W} / \mathrm{m}^{2}\right) \\
\text { dynamic sensitivity of } \\
\text { thermoreceptors }(\mathrm{s})\end{array}$ & $\mathrm{cl}$ & clothing node \\
\hline
\end{tabular}




\begin{abstract}
Thermoregulation models of the human body have been widely used in thermal comfort studies. The existing models are complicated and not fully verified for application in China. This paper presents a simplified thermoregulation model which has been statistically validated by the predicted and measured mean skin temperature in warm environments, including 21 typical conditions with 400 Chinese subjects. This model comprises three parts: i) the physical model; ii) the controlled system; and iii) the controlling system, and considers three key questions formerly ignored by the existing models including: a) the evaporation efficiency of regulatory sweat; b) the proportional relation of total skin blood flow and total heat loss by regulatory sweating against body surface area; and c) discrepancies in the mean skin temperatures by gender. The developed model has been validated to be within the $95 \%$ confidence interval of the population mean skin temperature in three cases.
\end{abstract}

Keywords:

Thermoregulation Model; Thermal Response; Skin Temperature 


\section{Introduction}

The thermal interaction of the human body with the environment involves two processes: i) the heat transfer between the human body and the thermal environment, simultaneously including radiation, convection, conduction, evaporation and respiration; and ii) the self-regulation function of the human body which responds to varied thermal environments, such as vasoconstriction, vasodilation, shivering and sweating (Cheng et al., 2012). Thermoregulation models of the human body are developed to simulate these two processes of interaction and predict the human thermal response under different thermal conditions and have been widely used in the field of physiology or thermal comfort studies (Parsons, 2014). An accurate thermoregulation model will help improve the accuracy of the current thermal comfort prediction models, and provide a basic theoretical analysis of the accuracy of the various models in application (De Giuli et al., 2014; Holopainen et al., 2014).

The simplified Gagge's 2-node model of thermoregulation (Gagge et al., 1971) is one of the most popular models in the field of thermal comfort study. Moreover, various complex thermoregulation models have been further developed by improving the modelling of body segmentation, particularly for heat insulation (Arezes et al., 2013), thermoregulatory systems and heat transfer (Fiala et al., 2001; Munir et al., 2009; Stolwijk, 1971; Werner and Webb, 1993; Xu and Werner, 1997), considering individual body characteristics (Takada et al., 2009; Zhang et al., 2001), and increasing the number of body segments to obtain a higher resolution temperature distribution on the skin surface (Huizenga et al., 2001; Tanabe et al., 2002).

These models are mostly developed based on European or American populations; however, their accuracy lacks effective validation (Yang et al., 2015a). There is little 
strong evidence in the existing research to show that existing models are applicable to the Chinese population. Thermal comfort prediction for the Chinese people still remains in an early research stage which is largely based on the modification of the traditional models but is still lacking systematic analysis (Zhou et al., 2013; Zhou et al., 2014). In this context, this paper aims to i) validate the predictive accuracy of the classic TwoNode model for the Chinese population; and ii) develop and validate a new simplified model based on the laboratory experiments.

The mean skin temperature was used for the validation of the developed model. In the existing studies, skin temperature has been demonstrated to be strongly related to the thermal interaction between the human body and the thermal environment, which is also an important indicator of thermal comfort (Parsons, 2014). It has been successfully used to validate increasingly complex and sophisticated predictive models for thermoregulatory responses, and to build thermal sensation models.

The systems predicting the interaction between people and their environment are complex (Andrew Thatcher, 2016). Here, the developed model shows advantages over many other existing models. The individual differences in human thermal responses are caused by some characteristics which can be quantitatively defined (age, height, weight, etc.), but may also contains some of the potential differences which are not so easily described such as the property of each layer of the body including core composition, muscle composition, fat composition and skin composition respectively. The mean basal metabolic rate of the Chinese population is re-measured in this study. It has allowed the simplification of the human body abstraction as a cylinder with its specific geometric dimensions and heat transfer direction, which cannot be provided by simply adjusting the parameters of existing models for the Chinese population. Meanwhile, the 
introduction of a cylinder model and the development of control plates make it more convenient and accurate in application compared to other models (Yang et al., 2015b).

\section{Description of the new model}

The proposed model consists of three parts: the physical model of the human body, the controlled system and the controlling system.

\subsection{Physical model of the human body}

In this physical model, the human body is abstracted as a cylinder consisting of four concentric layers: the core, muscle, fat and skin. A central pool of blood delivers the arterial blood to the capillaries and tissues in each layer, and meantime the blood flows back to the central pool through the veins. The schematic diagram of this physical model is shown in Figure 1. Assuming that the physical characteristics in each layer are uniform, the physical parameters of each layer are recalculated from the data of reference (Gordon et al., 1976; Stolwijk, 1971) and listed in Table 1. 


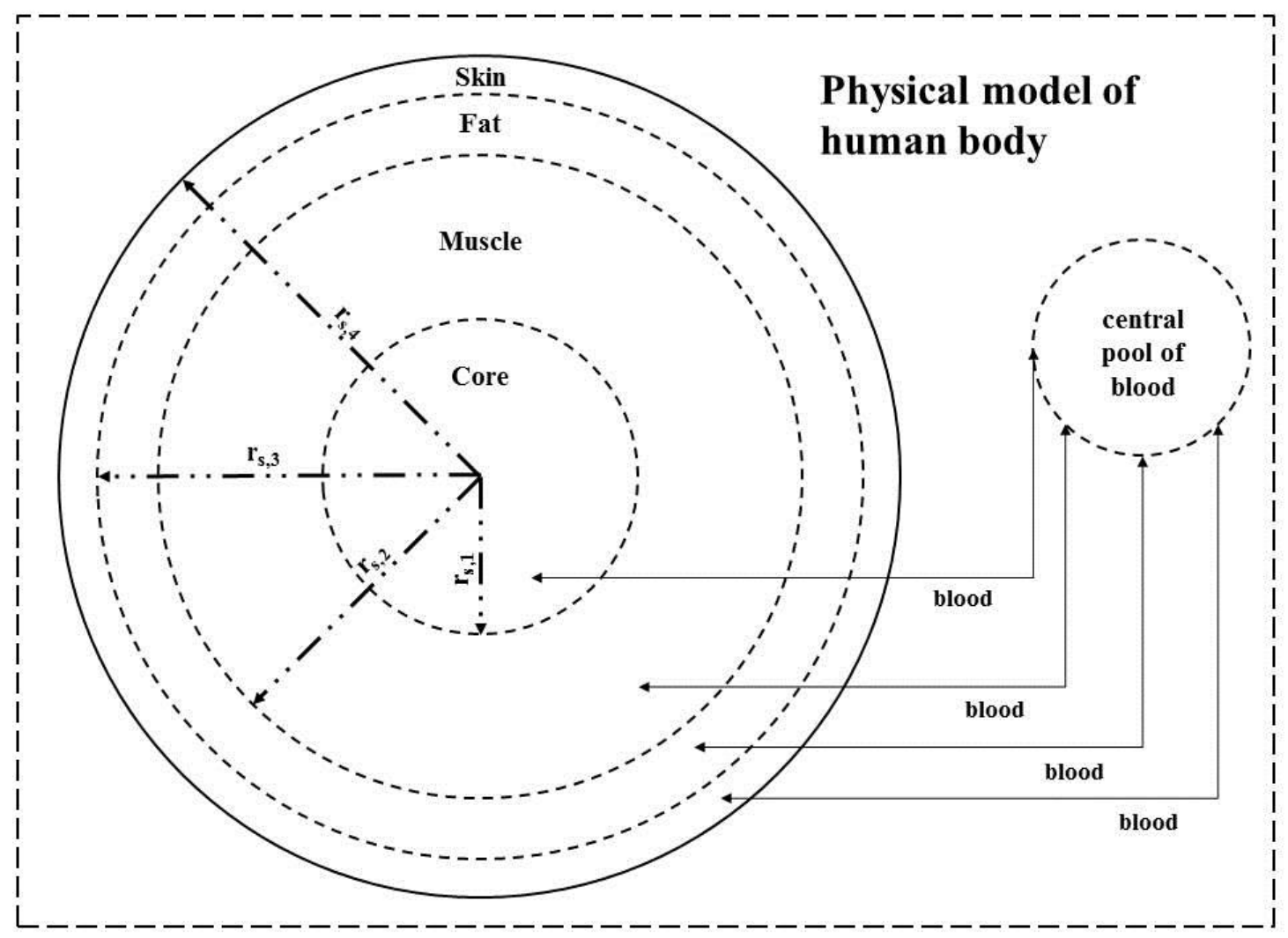

Figure 1. The schematic diagram of the physical model of the human body

Table 1. The physical parameters of the layers (Gordon et al., 1976; Stolwijk, 1971)

\begin{tabular}{lllll}
\hline Layer & Core & Muscle & Fat & Skin \\
\hline Density $\left(\mathrm{kg} / \mathrm{m}^{3}\right)$ & $\rho_{1}=977$ & $\rho_{2}=1115$ & $\rho_{3}=850$ & $\rho_{4}=1000$ \\
Specific heat $\left(\mathrm{J} /\left(\mathrm{kg} \bullet{ }^{\circ} \mathrm{C}\right)\right)$ & $c_{1=2968}$ & $c_{2}=3105$ & $c_{3}=2510$ & $c_{4}=3760$ \\
Heat conductivity coefficient $(\mathrm{w} /(\mathrm{m} \bullet \mathrm{k}))$ & $\lambda_{1}=0.42$ & $\lambda_{2}=0.66$ & $\lambda_{3}=0.21$ & $\lambda_{4}=0.21$ \\
& & & &
\end{tabular}

Considering the size of the physical model, the height dimension is far greater than the radius dimension. In the simulation, heat is only supposed to be transferred in a radial direction. Radial dependency of temperature is calculated in the model. In this paper, abbreviations with subscripts of $i=1,2,3,4$ represent the layers of core, muscle, fat and skin respectively. The subscripts $b$ and $c l$ represent the central blood and clothing nodes respectively. 
The geometric characteristics of the physical model can be calculated from the basic information of the human body (gender, height, weight and body fat percentage). The surface area $\mathrm{A}\left(\mathrm{m}^{2}\right)$ of a Chinese human body can be obtained by Equations 1 and 2 for male and female subjects (Wang, 1994). The length of the cylinder $L$ (m) and the external radius of layer $i$ (which is denoted by $r_{s, i}(\mathrm{~m})$ ) can be calculated by Equations 5 and 6 respectively.

$$
\begin{aligned}
& A=0.0057 H+0.0121 W+0.0882 \text { (for males) } \ldots \ldots \ldots \ldots \ldots \ldots \ldots \ldots \ldots . . . \ldots q . \text { (1) } \\
& A=0.0073 H+0.0127 W-0.2106 \text { (for females) } \ldots \ldots \ldots \ldots \ldots \ldots \ldots \ldots . . . . . . . . . .(2)
\end{aligned}
$$

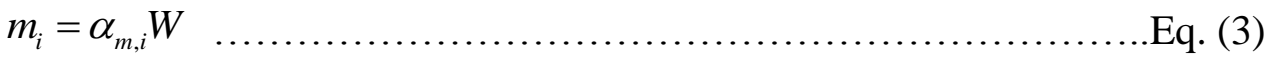

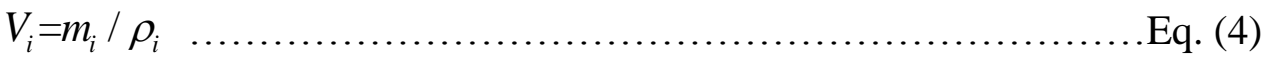

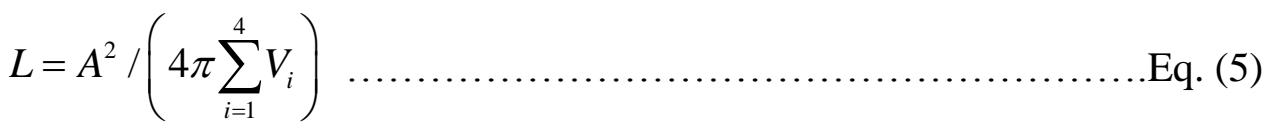

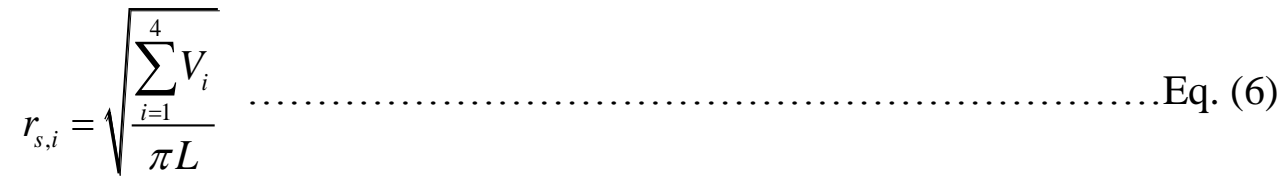

Where $H$ is the height $(\mathrm{cm}) ; W$ is the weight $(\mathrm{kg}) ; \alpha_{m, i}$ is the proportion of layer $i$ in the weight, which is recalculated by reference to Stolwijk (1971) and shown in Table 2; $V_{i}$ is the volume of layer $i\left(\mathrm{~m}^{3}\right)$.

Table 2. The proportions of layers by weight (Stolwijk, 1971)

\begin{tabular}{cccc}
\hline Core $\left(\alpha_{m, 1}\right)$ & Muscle and Fat $\left(\alpha_{m, 2}+\alpha_{m, 3}\right)$ & Skin $\left(\alpha_{m, 4}\right)$ & Total \\
\hline $22 \%$ & $73 \%$ & $5 \%$ & $100 \%$ \\
\hline
\end{tabular}

Therefore, gender, height, weight and body fat percentage can be used as the inputs for the physical model. The default values for Chinese male and female subjects in the model are set as $170 \mathrm{~cm}, 70 \mathrm{~kg}, 20 \%$ and $160 \mathrm{~cm}, 55 \mathrm{~kg}, 25 \%$ respectively (Yang, 2015). 


\subsection{Controlled system}

The controlled system is used to simulate the internal heat transfer of the body and the heat transfer between the body surface and the thermal environment.

Based on the physical model of the human body, the scheme of thermal interaction for humans with the environment can be seen from Figure 2.

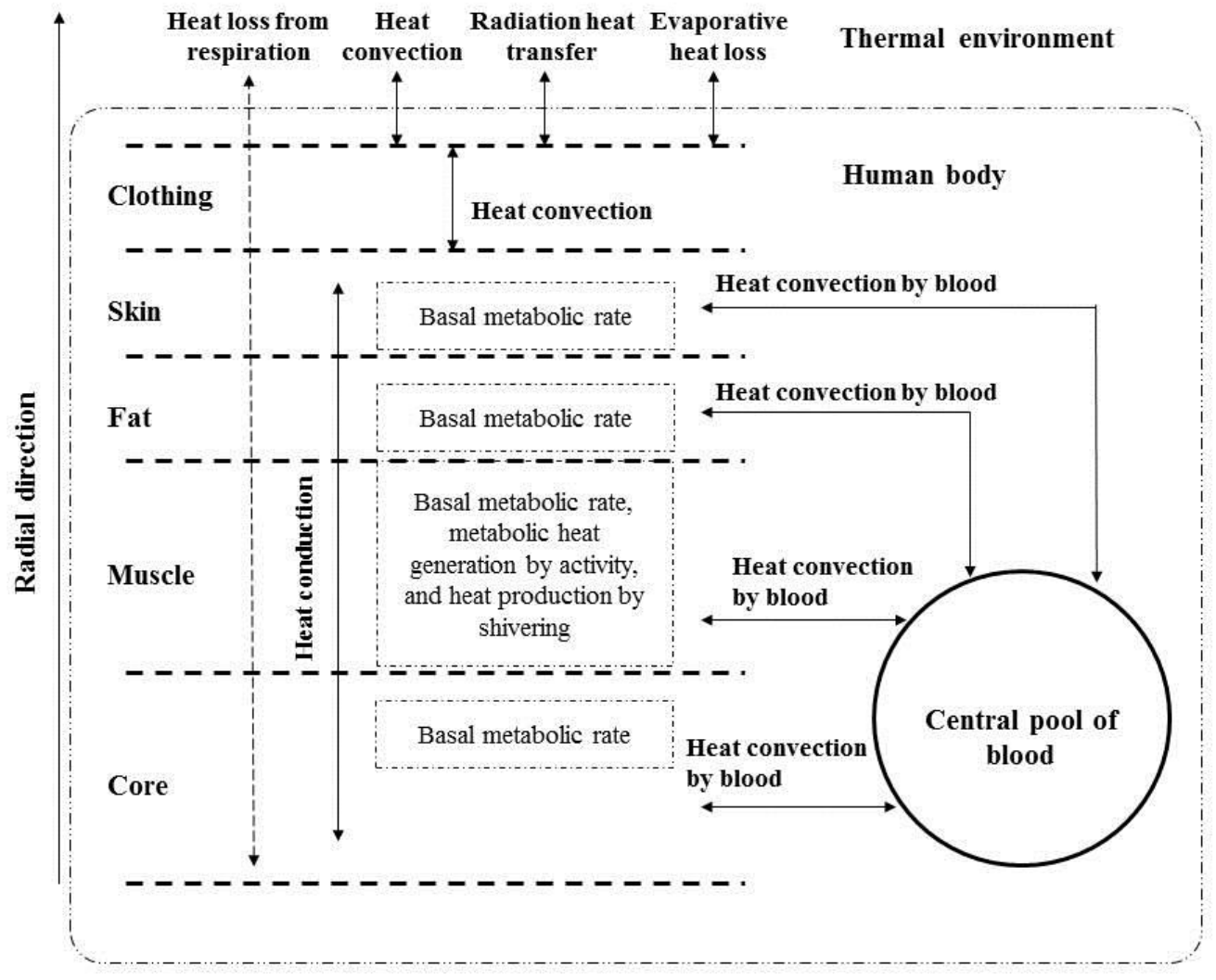

Figure 2. The scheme for the thermal interaction of humans with the environment

\subsubsection{Energy equation}

The energy equation in a one-dimensional cylindrical coordinate system based on classical heat transfer theory is:

$\rho_{i} c_{i} \frac{\partial T_{i}}{\partial t}=\lambda_{i}\left(\frac{\partial^{2} T_{i}}{\partial r^{2}}+\frac{1}{r} \frac{\partial T_{i}}{\partial r}\right)+M_{b, i}+M_{w, i}+M_{s, i}+\beta Q_{i} c_{b} \rho_{b}\left(T_{b}-T_{i}\right)$

Where, $T_{i}(r, t)$ is the temperature of tissue $\left({ }^{\circ} \mathrm{C}\right) ; M_{b, i}(r)$ is the heat production by 
basic metabolism in Watts per cubic metre $\left(\mathrm{W} / \mathrm{m}^{3}\right) ; M_{w, i}(r, t)$ is the heat production by activity metabolism per cubic metre $\left(\mathrm{W} / \mathrm{m}^{3}\right) ; M_{s, i}(r, t)$ is the heat production by shivering per cubic metre $\left(\mathrm{W} / \mathrm{m}^{3}\right) ; \beta$ is the counter-current factor, by which the approximate heat exchange between arterial blood and venous blood is considered. The effect of the counter-current usually takes place in cold conditions and $\beta$ equals 1 in this paper for warm conditions. $Q_{i}(r, t)$ is the blood flow per cubic metre $\left[\mathrm{m}^{3} /\left(\mathrm{s} \cdot \mathrm{m}^{3}\right)\right]$; $c_{b}$ is the specific heat of central blood, which equals $3,760\left[\mathrm{~J} /\left(\mathrm{kg} \cdot{ }^{\circ} \mathrm{C}\right)\right] ; \rho_{b}$ is the density of central blood, which equals $1,000\left(\mathrm{~kg} / \mathrm{m}^{3}\right) ; T_{b}$ is the temperature of central blood $\left({ }^{\circ} \mathrm{C}\right)$.

Table 3. The mean basal metabolic rate of the Chinese population $M_{b}\left(\mathrm{~W} / \mathrm{m}^{2}\right)(\mathrm{Yao}, 2005)$

\begin{tabular}{cccccccc}
\hline \multirow{2}{*}{ Gender } & \multicolumn{7}{c}{ Age } \\
& $11-15$ & $16-17$ & $18-19$ & $20-30$ & $31-40$ & $41-50$ & Over 51 \\
\hline Male & 54.28 & 53.69 & 46.14 & 43.82 & 44.05 & 42.77 & 41.38 \\
Female & 47.88 & 50.44 & 42.77 & 40.68 & 40.79 & 39.52 & 38.47 \\
\hline
\end{tabular}

$M_{b, i}$ can be calculated from the total basal metabolic rate $M_{b}\left(\mathrm{~W} / \mathrm{m}^{2}\right)$, which is related to gender and age; the data for the Chinese population is shown in Table 3 (Yao, 2005):

$M_{b, i}=\delta_{i} M_{b} A / V_{i}$

Where, $\delta_{i}$ is the proportion of the basal metabolic rate taken up by layer $i$.

Gordon et al. (1976) gave the reference value as shown in Table 4.

Table 4. The proportion of the basal metabolic rate for each layer of the human body

(Gordon et al., 1976)

\begin{tabular}{ccccc}
\hline Core $\left(\delta_{1}\right)$ & Muscle $\left(\delta_{2}\right)$ & Fat $\left(\delta_{3}\right)$ & Skin $\left(\delta_{4}\right)$ & Total \\
\hline $4.1 \%$ & $74.9 \%$ & $0.7 \%$ & $20.9 \%$ & $100.0 \%$ \\
\hline
\end{tabular}


Assuming $M_{w, i}$ is only related to the activity level and this energy is produced by the muscle, the following equations are used to describe $M_{w, i}$ :

$M_{w, 1}=M_{w, 3}=M_{w, 4}=0$

$M_{w, 2}=\left(M-M_{b}\right) A / V_{2}$

Where, $M$ is the metabolic heat generation for a certain activity $\left(\mathrm{W} / \mathrm{m}^{2}\right)$, which is provided by the international standard (ASHRAE-55, 2004); $M_{b}$ is assumed to be the basal metabolic rate for the population aged from 20-30.

$M_{s, i}$ and $Q_{i}$ are variable and controlled by the controlling system.

$T_{b}$ is considered to be independent of the radius and determined by the energy equation:

$$
\rho_{b} c_{b} Q_{b} \frac{d T_{b}}{d t}=\sum_{i=1}^{4} \int_{r_{s, i-1}}^{r_{s, i}} \beta \rho_{b} c_{b} Q_{i}\left(T_{v, i}-T_{b}\right)
$$

Where, $r_{s, 0}$ represents the radius of the cylinder's centre, which is equal to $0 ; T_{v, i}(r, t)$ is the venous temperature $\left({ }^{\circ} \mathrm{C}\right)$, and it is assumed to be equal to the temperature of the adjacent tissue, that is:

$T_{v, i}(r, t)=T_{i}(r, t)$

$Q_{b}$ is the total blood flow to the cylinder $\left(\mathrm{m}^{3}\right)$ and is obtained by integration over the volume of a cylinder with length L:

$Q_{b}=\sum_{i=1}^{4} 2 \pi L \int_{r_{s, i-1}}^{r_{s, i}} Q_{i} r d r$

\subsubsection{Boundary and initial conditions}

The boundary condition at the centre of the cylinder is: 
$\left.\frac{\partial T_{i}}{\partial r}\right|_{r=0}=$ Cres + Eres

Where, Cres and Eres are the convective and evaporative heat loss from respiration per body surface area respectively $\left(\mathrm{W} / \mathrm{m}^{2}\right)($ Fanger, 1970):

$C_{r e s}=0.0014 M\left(34-T_{a}\right)$

$E_{\text {res }}=0.0000173 M\left(5867-P_{a}\right)$

The continuity of temperature and heat flux at an interface between two layers of different tissues is expressed in Equations 17 and 18.

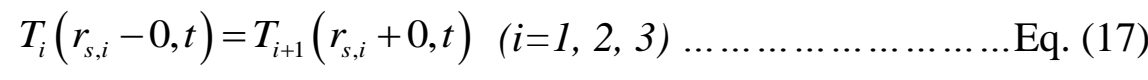

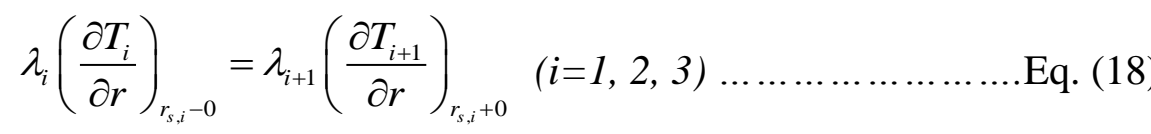

At the skin surface, the heat brought to the surface by conduction from the deep body is equal to the heat removed from the surface by evaporation and conduction. Therefore, the boundary condition at the skin surface is:

$\lambda_{i} \frac{\partial T_{i}}{\partial r}=-f_{c l} \frac{T_{i}-T_{c l}}{0.155 I_{c l}}-E_{s w}-E_{d i f f} \quad\left(i=4, r=r_{s, 4}\right)$

Where, $I_{c l}(t)$ is the total thermal insulation of clothing (clo), which can be estimated or calculated by ISO 7730 (ISO-7730, 2005); $E_{s w}(t)$ is the evaporative heat loss by sweating per body surface area $\left(\mathrm{W} / \mathrm{m}^{2}\right) ; E_{\text {diff }}(t)$ is the diffusion evaporative heat loss per body surface area $\left(\mathrm{W} / \mathrm{m}^{2}\right)$.

$f_{c l}(t)$ is the clothing area factor, which can be roughly estimated by Equation 20 (McCullough et al., 1985):

$f_{c l}=1.0+0.3 I_{c l}$ Eq. (20)

$E_{s w}$ is regulated by the thermoregulatory controlling system; $E_{\text {diff }}$ can be calculated 
from Equation 21 (Fanger, 1970).

$$
E_{\text {diff }}(t)=0.00305\left(256 T\left(r_{s, 4}, t\right)-3373-P_{a}\right)
$$

Considering the fact that people are usually in light clothing in warm conditions, the clothing node is simplified as follows:

$$
m_{c l} c_{c l} \frac{d T_{c l}}{d t}=A \frac{T_{i}-T_{c l}}{0.155 I_{c l}}-A(C+R)
$$

Where, $m_{c l}$ is the weight of the clothing $(\mathrm{kg})$, the default value is set as $0.2 \mathrm{~kg}$ in warm conditions; $c_{c l}$ is the specific heat of clothing $\left(\mathrm{J} /\left(\mathrm{kg} \cdot{ }^{\circ} \mathrm{C}\right)\right)$, Yi et al. (2004) provide the data for some common materials, the value for cotton is 1,210 .

$C(t)$ and $R(t)$ are the convective and radiative heat losses from the outer surface of a clothed body, both of which are related to the difference between the mean temperature of the outer surface of the clothed body $T_{c l}\left({ }^{\circ} \mathrm{C}\right)$ and the mean air temperature $T_{a} \quad\left({ }^{\circ} \mathrm{C}\right)$, as shown in Equation 23.

$C=f_{c l} h_{c}\left(T_{c l}-T_{a}\right)$ Eq. (23)

Where, $h_{c}$ is the convective heat transfer coefficient $\left(\mathrm{W} / \mathrm{m}^{2} \cdot{ }^{\circ} \mathrm{C}\right)$; Equations for estimating $h_{c}$ are expressed as (Fanger, 1970):

$$
\begin{aligned}
& h_{c}=2.38\left(T_{c l}-T_{a}\right)^{0.25} \quad\left(\text { when } 2.38\left(T_{c l}-T_{a}\right)^{0.25}>12.1 \sqrt{V_{a}}\right) \\
& h_{c}=12.1 \sqrt{V_{a}} \quad\left(\text { when } 12.1 \sqrt{V_{a}} \geq 2.38\left(T_{c l}-T_{a}\right)^{0.25}\right) \ldots \ldots \ldots \ldots
\end{aligned}
$$

$$
R=f_{c l} \varepsilon \sigma \frac{A_{r}}{A}\left[\left(T_{c l}+273\right)^{4}-\left(T_{r}+273\right)^{4}\right]
$$

Where,

$\varepsilon=$ average emissivity of clothing or body surface, (dimensionless).

$\sigma=$ Stefan-Boltzmann constant, $5.67 \times 10^{-8} \mathrm{~W} /\left(\mathrm{m}^{2} \cdot \mathrm{K}^{4}\right)$. 
$A_{r}=$ effective radiation area of body, $m^{2}$.

$T_{r}=$ mean radiant temperature, ${ }^{\circ} \mathrm{C}$

The ratio $A_{r} / A$ is 0.70 for a sitting person and 0.73 for a standing person (Fanger, 1970). Emissivity $\varepsilon$ is close to unity (typically 0.95 ), unless special reflective materials are used or high-temperature sources are involved.

The mean radiant temperature $T_{r}$ can be determined by the measurement of the black globe temperature $\left(T_{g}\right)$ and the air temperature and air velocity at the level of this globe (ISO-7726, 2001).

1) In the case of natural convection:

$T_{r}=\left[\left(T_{g}+273\right)^{4}+\frac{0.25 \times 10^{8}}{\varepsilon_{g}}\left(\frac{\left|T_{g}-T_{a}\right|}{D}\right)^{1 / 4} \times\left(T_{g}-T_{a}\right)\right]^{1 / 4}-273 \ldots \ldots \ldots \ldots \ldots . . . . . . . .(27)$

Where, $\varepsilon_{g}$ is the emissivity of the black globe (dimensionless); $D$ is the diameter of the globe $(m)$.

For the standard globe $D=0.15 \mathrm{~m}, \varepsilon_{g}=0.95$ (matt black paint) and Equation 27 becomes:

$T_{r}=\left[\left(T_{g}+273\right)^{4}+0.4 \times 10^{8}\left|T_{g}-T_{a}\right|^{1 / 4} \times\left(T_{g}-T_{a}\right)\right]^{1 / 4}-273$

2) In the case of forced convection:

$T_{r}=\left[\left(T_{g}+273\right)^{4}+\frac{1.1 \times 10^{8} \times V_{a}^{0.6}}{\varepsilon_{g} \times D^{0.4}}\left(T_{g}-T_{a}\right)\right]^{1 / 4}-273$

For the standard globe:

$T_{r}=\left[\left(T_{g}+273\right)^{4}+2.5 \times 10^{8} \times V_{a}^{0.6}\left(T_{g}-T_{a}\right)\right]^{1 / 4}-273$

The initial conditions which specify the values of all dependent variables at time zero 
should be provided. The initial values may be equilibrium values which are obtained from a previous steady-state calculation (denoted as $\left.T_{a}\right|_{t=0},\left.T_{r}\right|_{t=0},\left.v_{a}\right|_{t=0},\left.R H_{a}\right|_{t=0}$, $\left.I_{c l}\right|_{t=0},\left.M\right|_{t=0}$ ), or they may be non-equilibrium values which result from a previous transient process. In either case, they consist of body temperature specifications at the instant the transient process begins, which are denoted as $\left.T_{i}\right|_{t=0}$.

\subsection{Controlling system}

The controlling system is used to simulate the thermoregulatory control mechanisms in the human body. It includes the regulation of blood flow, sweating and shivering. The proposed controlling system is based on the traditional controlling system provided in Stolwijk (1971) and further improved by an empirical formula.

\subsubsection{Signal input}

The input for the controlling system consists of two signals collected from the core layer and skin layer respectively. These signals are integrated temperatures formed by the hypothalamus temperature and the skin temperature, which can be expressed as:

$$
\begin{aligned}
& E r r_{c}=T\left(r_{s, 0}\right)-T_{s e t, c}+R_{d} \times T^{\prime}\left(r_{s, 0}\right) \\
& E r r_{s}=T\left(r_{s, 4}\right)-T_{s e t, s}+R_{d} \times T^{\prime}\left(r_{s, 4}\right)
\end{aligned}
$$

Where, $\operatorname{Err}_{c}$ are the input signals of the core layer $\left({ }^{\circ} \mathrm{C}\right)$ and $\operatorname{Err} r_{s}$ are the input signals of skin layer $\left({ }^{\circ} \mathrm{C}\right) ; T\left(r_{s, 0}\right)$ represents the temperature of the thermoreceptor in the hypothalamus and $T\left(r_{s, 4}\right)$ represents the temperature of the thermoreceptor under the skin; $T_{s e t, c}$ and $T_{s e t, s}$ are the temperature set points for the core and skin respectively 
$\left({ }^{\circ} \mathrm{C}\right) ; R_{d}$ is the dynamic sensitivity of the thermoreceptor and $T^{\prime}$ represents the temperature change rate $\left({ }^{\circ} \mathrm{C} / \mathrm{s}\right)$.

The set point temperatures $\left(T_{\text {set, } c}\right.$ and $\left.T_{\text {set }, s}\right)$ can be acquired by simulating the body under a thermally neutral condition with no work and no regulatory control. The experiment was designed to show the body's adaptation in a neutral thermal environment. The human body was in a steady state at the end of the exposure stage when the change rate of the body's average skin temperature was $<0.01^{\circ} \mathrm{C} / \mathrm{min}$. The steady neutral environmental parameters and human body temperature set points are recorded in Tables 5 and 6. Parameters for male and female subjects to achieve thermal neutrality were obtained by the previous experimental study and these two sets are listed in Table 5. The calculated set point temperatures are different for each gender and results are shown in Table 6.

Table 2. Parameters for a thermally neutral condition

\begin{tabular}{ccccccc}
\hline Parameters & $\mathrm{T}_{\mathrm{a}}\left({ }^{\circ} \mathrm{C}\right)$ & $\mathrm{RH}(\%)$ & $\mathrm{V}_{\mathrm{a}}(\mathrm{m} / \mathrm{s})$ & $\mathrm{T}_{\mathrm{g}}\left({ }^{\circ} \mathrm{C}\right)$ & $\mathrm{M}\left(\mathrm{W} / \mathrm{m}^{2}\right)$ & $\mathrm{I}_{\mathrm{cl}}(\mathrm{clo})$ \\
\hline Male & 26 & 74.11 & 0.05 & 26.47 & 58.15 & 0.4 \\
Female & 26.2 & 73.55 & 0.06 & 26.42 & 55.15 & 0.4 \\
\hline
\end{tabular}

Table 6. The set point temperatures of the human body

\begin{tabular}{ccc}
\hline Temperature set points $\left({ }^{\circ} \mathrm{C}\right)$ & $T_{\text {set, },}$ & $T_{\text {set,s }}$ \\
\hline Male & 36.94 & 34.16 \\
Female & 36.67 & 33.8 \\
\hline
\end{tabular}

The value or the quantitative analysis for $R_{d}$ is not totally revealed according to the existing references (Kobayashi and Tanabe, 2013; Tanabe et al., 2002), it represents the 
human sensitivity to the change of the ambient temperature. Here we chose empirical values for the prediction accuracy of the model: when $T^{\prime}>0, R_{d}=0(0)$; when $T^{\prime}<0$, $R_{d}=0$ (s) for males, and $R_{d}=1800$ (s) for females (Yang, 2015).

\subsubsection{Vasomotion}

The total blood flow for layers $B F_{i}(1 / \mathrm{h})$ is calculated by Equations 33 to 36 . The blood flow for core and fat tissue remains constant. For muscle compartments, a blood flow of $1.0 \mathrm{l} / \mathrm{h}$ was required for $1.16 \mathrm{~W}$ metabolic heat production (Tanabe et al., 2002). The skin blood flow is controlled by the effect of vasodilation or vasoconstriction in the thermoregulation system, which is assumed to be proportional to the body surface $A$.

$$
B F_{1}=255
$$

$B F_{2}=14.74+\left(M_{w, 2}+M_{s h i}\right) \times A / 1.16$

$B F_{3}=3.5$

$B F_{4}=\frac{11.89+D L}{1+S T} \times 2^{E r r_{s} / 10} \times \frac{A}{1.89}$ Eq. (36)

$D L=117 E r r_{c}+7.5 E r r_{s} \quad($ if $\quad D L<0$, then $D L=0)$

$S T=-0.63 E r r_{c}-0.63 E r r_{s} \quad($ if $\quad S T<0$, then $S T=0)$

Therefore:

$Q_{i}=0.278 \times 10^{-6} \mathrm{BF}_{i} / V_{i}$ Eq. (39)

\subsubsection{Sweating}

The heat loss by regulatory sweating per body surface area $E_{s w}\left(\mathrm{~W} / \mathrm{m}^{2}\right)$ is calculated by Equations 40 and 41:

For males, 
$E_{s w}=\left(223 E r r_{c}+20 E r r_{s}\right) 2^{E r_{s} / 10} / 1.89$

For females,

$E_{s w}=\left(111 E r r_{c}+10 E r r_{s}\right) 2^{E r r_{s} / 10} / 1.89$

$E_{s w}$ shows differences according to gender, the value for females is smaller than that for males under the same conditions. The total heat loss by regulatory sweating is also proportional to the body surface area A.

\subsubsection{Shivering heat production}

The shivering heat production per body surface area $\left(\mathrm{W} / \mathrm{m}^{2}\right)$ is calculated by Equation 42:

$M_{s h i}=24.4 E r r_{c} \operatorname{Err}_{s} / A$ (if $E r r_{c}>0$ or $E r r_{s}>0$, then $M_{s h i}=0$ ) Eq. (42)

\subsection{Numerical solution and computer programming}

The numerical solution for solving the thermoregulation model is an explicit method with centred finite difference. The spatial grid is radially divided with the spacing $\Delta r=0.002 m$. The time increment is set as $1 \mathrm{~s}$.

The simulation program is written in Matlab 2010 and the programming flow chart is shown in Figure 3. It consists of five parts: INPUT, PHYSICAL, CONTROLLING, CONTROLLED and OUTPUT. Their functions are shown Table 7 below:

Table. 7. Model structure distribution

\begin{tabular}{cc}
\hline Model Structure & Definition and Coverage \\
\hline Human body model & Build physical model of human body and calculate the \\
\hline
\end{tabular}


geometric, physiological and physical parameters of the model.

Controlling system

Calculate the parameters of the controlling system based on the human thermal physiological responses and thermal adaptability.

Controlled system Calculate the body temperature according to the equations in a controlled system based on the application of classical heat transfer theory between the human body and the dynamic thermal environment.

\begin{tabular}{ll}
\hline Input parameters & \multicolumn{1}{c}{ Environment parameters } \\
\cline { 2 - 2 } & Mean air temperature, Mean radiant temperature, Mean \\
& air velocity, Relative humidity, Metabolic rate, Thermal \\
& insulation of clothing. \\
& Hender, age, height, weight, body fat percentage. \\
\hline Output parameters & Body temperature in any transient of the thermal \\
process.
\end{tabular}




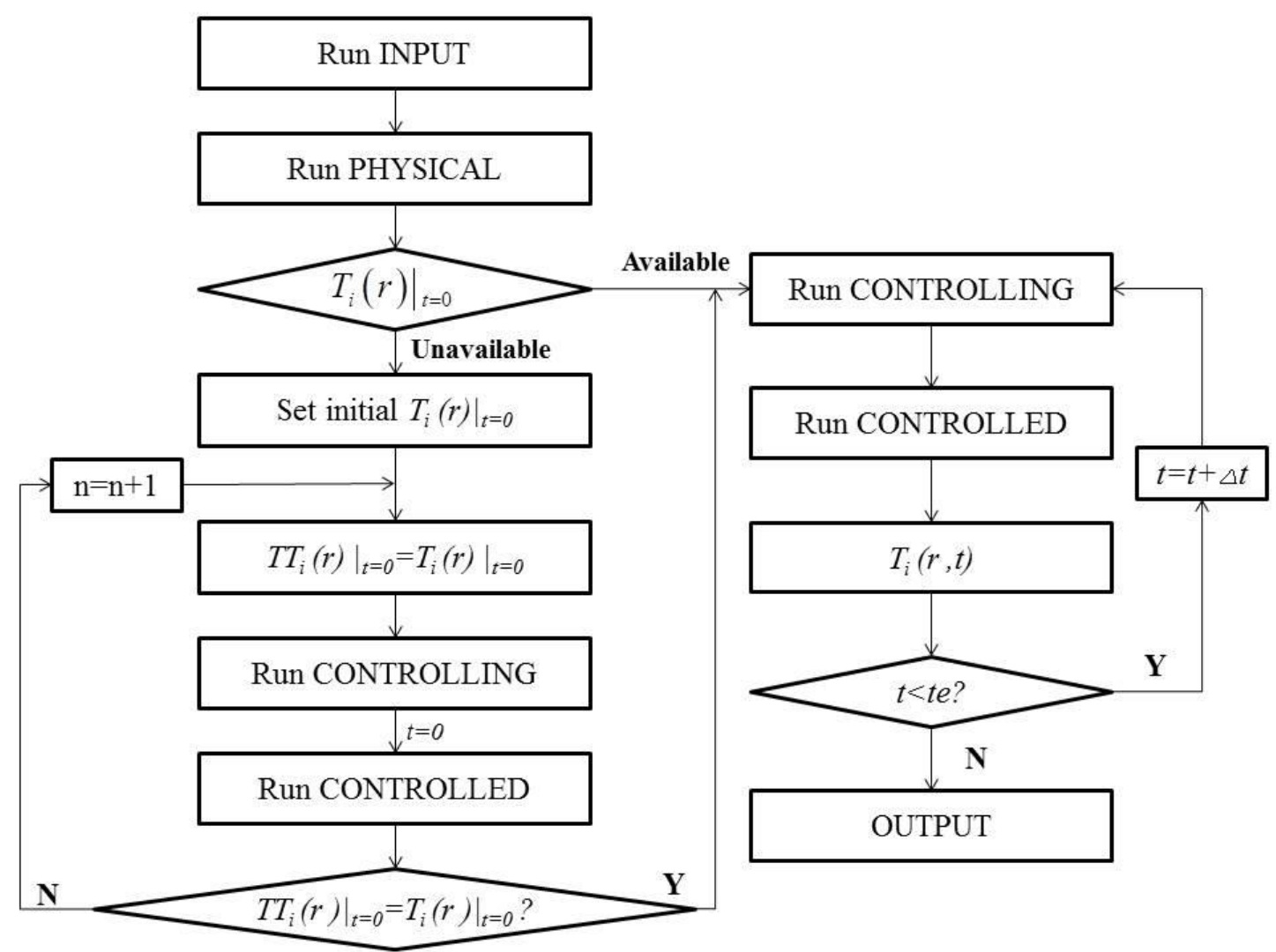

Figure 3. Flow chart of the simulation program.

( $\mathrm{n}$ : calculated numbers; $\mathrm{t}$ : calculated time; $\Delta \mathrm{t}$ :time step; te: simulation time)

\section{Validation of the models}

A model is by definition simpler than the system it attempts to represent. Thus, validation by comparing the model prediction with the experimental data from human subjects is necessary. Not only does this process identify the prediction accuracy of the model, but it also helps to define the range of conditions in which the model is applicable.

Skin temperature is strongly related to the thermal interaction between the human body and the thermal environment (Gagge et al., 1971; Stolwijk, 1971), which is also an important indicator of thermal comfort (Cheng et al., 2012; Fanger, 1970). It has been successfully used to validate increasingly complex and sophisticated predictive models for thermoregulatory responses (Munir et al., 2009; Yi et al., 2004; Zolfaghari and 
Maerefat, 2010), and to build thermal sensation models (Lomas et al., 2003; Wang, 1994). Therefore, in this paper we choose the mean skin temperature to validate the accuracy of the models.

The method for the model validation can be found in Yang et al. (2015a). According to this approach, the accuracy of the model has been primarily examined by inferential statistical analysis, and then assessed through the Bland-Altman method (Bland, J.M. and Altman, D.G., 1986) if necessary. By the validation, the accuracy of the model can be classified into three levels: I-The model's prediction is sufficiently statistically accurate; II-The model's prediction is sufficiently accurate to be used in applications; III-The model's prediction is not sufficiently accurate.

Three series of experimental data from human subjects under the typical warm conditions have been obtained, they are:

Case 1: clothed subjects in step-changing environments $\left(26^{\circ} \mathrm{C}\right.$ to $28^{\circ} \mathrm{C} 29^{\circ} \mathrm{C} / 30^{\circ} \mathrm{C} / 32^{\circ} \mathrm{C} / 34^{\circ} \mathrm{C}$, then back to $26^{\circ} \mathrm{C}$ ).

Case 2: nude subjects in step-changing environments $\left(28^{\circ} \mathrm{C}\right.$ to $\left.32^{\circ} \mathrm{C} / 35^{\circ} \mathrm{C}\right)$.

Case 3: clothed subjects in typical warm, steady state, environments.

The proposed model has been validated by all the three sets of experiments with a total of 400 subjects. For comparison purposes, the existing Two-Node model, which is regarded as one of the most classic simplified thermoregulation models in thermal comfort studies, has also been validated by comparing its predictions with the experimental data of Case 1.

\subsection{Case 1}

A temperature step-changing experiment was carried out to validate the performance of the models under transient conditions. Ten male and ten female healthy subjects were 
recruited randomly to participate in the experiment. During the experiment, all the subjects were required to wear uniform clothing including light long-sleeve cotton shirts and trousers, and light shoes with a total clothing insulation level of $0.4 \mathrm{clo}$ (1clo equals $\left.0.155 \mathrm{~m}^{2} \cdot \mathrm{K} / \mathrm{W}\right)$. Five environment conditions were designed in this experiment. In each condition, the subjects firstly experienced a step-change thermal process from a neutral environment (Environment I) to a typical warm environment (Environment II), and then stayed in Environment II for 1,800 seconds. The subjects then returned to the neutral condition (Environment III) for another 1,800 seconds. The basic information of the subjects and the environment conditions in Case 1 are listed in Tables 8 and 9 respectively.

Table 8. Subjects' information in Case 1 (mean \pm standard deviation)

\begin{tabular}{ccc}
\hline Subjects & Male & Female \\
\hline Age & $24 \pm 1$ & $24 \pm 1$ \\
Height (m) & $170 \pm 7$ & $159 \pm 6$ \\
Weight (kg) & $58 \pm 5$ & $51 \pm 8$ \\
Body fat percentage (\%) & $16.9 \pm 2.97$ & $25.6 \pm 5.3$ \\
Clothing insulation (clo) & $0.4 \pm 0$ & $0.4 \pm 0$ \\
Activity level (met) & $1.0 \pm 0$ & $1.0 \pm 0$ \\
\hline
\end{tabular}

Table 9. Thermal conditions of the experiment in Case 1 (mean \pm standard deviation)

\begin{tabular}{|c|c|c|c|c|c|}
\hline & Case 1 & $\begin{array}{c}\text { Air } \\
\text { Temperature } \\
\left({ }^{\circ} \mathrm{C}\right)\end{array}$ & $\begin{array}{c}\text { Relative } \\
\text { Humidity } \\
(\%)\end{array}$ & $\begin{array}{l}\text { Air Velocity } \\
(\mathrm{m} / \mathrm{s})\end{array}$ & $\begin{array}{c}\text { Globe } \\
\text { Temperature }\left({ }^{\circ} \mathrm{C}\right)\end{array}$ \\
\hline \multirow{3}{*}{ Condition 1} & Environment I & $26.0 \pm 0.2$ & $71.9 \pm 3.0$ & $0.05 \pm 0.00$ & $26.4 \pm 0.2$ \\
\hline & Environment II & $28.2 \pm 0.1$ & $54.6 \pm 0.2$ & $0.18 \pm 0.04$ & $28.4 \pm 0.1$ \\
\hline & Environment III & $26.0 \pm 0.2$ & $70.5 \pm 3$ & $0.06 \pm 0.01$ & $26.5 \pm 0.2$ \\
\hline
\end{tabular}




\begin{tabular}{|c|c|c|c|c|c|}
\hline & Environment I & $26.1 \pm 0.1$ & $77.3 \pm 2.8$ & $0.05 \pm 0.01$ & $26.5 \pm 0.1$ \\
\hline \multirow[t]{3}{*}{ Condition 2} & Environment II & $29.0 \pm 0.1$ & $54.7 \pm 0.8$ & $0.17 \pm 0.07$ & $29.3 \pm 0.1$ \\
\hline & Environment III & $26.2 \pm 0.2$ & $75.9 \pm 2.5$ & $0.05 \pm 0.01$ & $26.6 \pm 0.1$ \\
\hline & Environment I & $26.1 \pm 0.2$ & $71.5 \pm 3.9$ & $0.06 \pm 0.01$ & $26.5 \pm 0.3$ \\
\hline \multirow[t]{3}{*}{ Condition 3} & Environment II & $30.3 \pm 0.2$ & $58.1 \pm 3.3$ & $0.14 \pm 0.09$ & $30.4 \pm 0.2$ \\
\hline & Environment III & $26.0 \pm 0.3$ & $71.0 \pm 3.6$ & $0.06 \pm 0.02$ & $26.5 \pm 0.3$ \\
\hline & Environment I & $26.5 \pm 0.3$ & $70.8 \pm 3.7$ & $0.18 \pm 0.04$ & $26.5 \pm 0.3$ \\
\hline \multirow[t]{3}{*}{ Condition 4} & Environment II & $32.0 \pm 0.1$ & $53.9 \pm 3.9$ & $0.20 \pm 0.03$ & $32.0 \pm 0.1$ \\
\hline & Environment III & $26.8 \pm 0.3$ & $69.6 \pm 4.9$ & $0.08 \pm 0.02$ & $26.8 \pm 0.3$ \\
\hline & Environment I & $26.0 \pm 0.1$ & $77.2 \pm 1.1$ & $0.05 \pm 0.01$ & $26.3 \pm 0.2$ \\
\hline \multirow[t]{2}{*}{ Condition 5} & Environment II & $33.8 \pm 0.1$ & $56.1 \pm 0.7$ & $0.20 \pm 0.04$ & $33.9 \pm 0.0$ \\
\hline & Environment III & $26.2 \pm 0.1$ & $75.4 \pm 2.5$ & $0.06 \pm 0.01$ & $26.5 \pm 0.1$ \\
\hline
\end{tabular}

During the experiment, skin temperature measurements at 13 locations on the body including the forehead, chest, back, upper arm (right and left), lower arm (right and left), dorsal hand (right and left), calf (right and left), and thigh (right and left) were performed automatically with a frequency of $0.5 \mathrm{~Hz}$. The 8-point weighted method (Gagge and Nishi, 2011) was adopted to calculate the body mean skin temperature $\left(T_{s k}\right)$ as represented by Equation (43):

$\mathrm{T}_{\text {sk }}=0.07 \mathrm{~T}_{\text {forehead }}+0.175 \mathrm{~T}_{\text {chest }}+0.175 \mathrm{~T}_{\text {back }}+0.07 \mathrm{~T}_{\text {upper arm }}+0.07 \mathrm{~T}_{\text {lower arm }}+0.05 \mathrm{~T}_{\text {hand }}+$

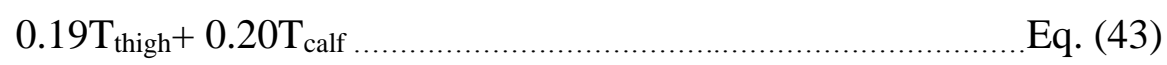

In order to validate and compare the performance of the new model and the classic Two-Node Gagge Model (Gagge et al., 1971), the two models were operated to simulate the above thermal process. The predicted and measured skin temperatures during the 3,600 seconds in the experiments of Case 1 are shown in Figure 4 and Figure 5 for male 
and female subjects respectively. According to the model evaluation method (Yang et al., 2015a), statistical validation is conducted by comparing model predictions with the confidence intervals of the population means. For the model, all the predictions lie within the $95 \%$ confidence interval of the population means, indicating no statistically significant difference between the population means and the predictions of the model. The accuracy of the new model in predicting the transient responses for subjects with light clothing is evaluated as Level I. However, for the Gagge Model, significant differences were found between the model predictions and the measured data, especially in high-temperature conditions (Conditions 4 and 5). The Gagge Model cannot be statistically validated in this case. Further empirical validation for the Gagge Model is carried out by the Bland-Altman method (Bland, J.M. and Altman, D.G., 1986; Yang et al., 2015a). The 'limit of agreement' of the predictions of the Gagge Model and population means are calculated as $[-0.49,0.09]$ and $[-0.52,0.19]$ for males and females respectively, which suggests the predictions of the Gagge Model may be $0.49^{\circ} \mathrm{C}$ below or $0.09^{\circ} \mathrm{C}$ above the measured sample means for male subjects (similarly $0.52^{\circ} \mathrm{C}$ below or $0.19^{\circ} \mathrm{C}$ above for female subjects). The Gagge Model is unacceptable if we regard the accuracy requirement for the skin temperature in thermal comfort studies as 'the difference between the model prediction and the sample mean in most cases must be less than $0.3^{\circ} \mathrm{C}^{\prime}$, and it should be evaluated as Level III Therefore, predictions from our new model are superior to the Gagge model in case 1. 


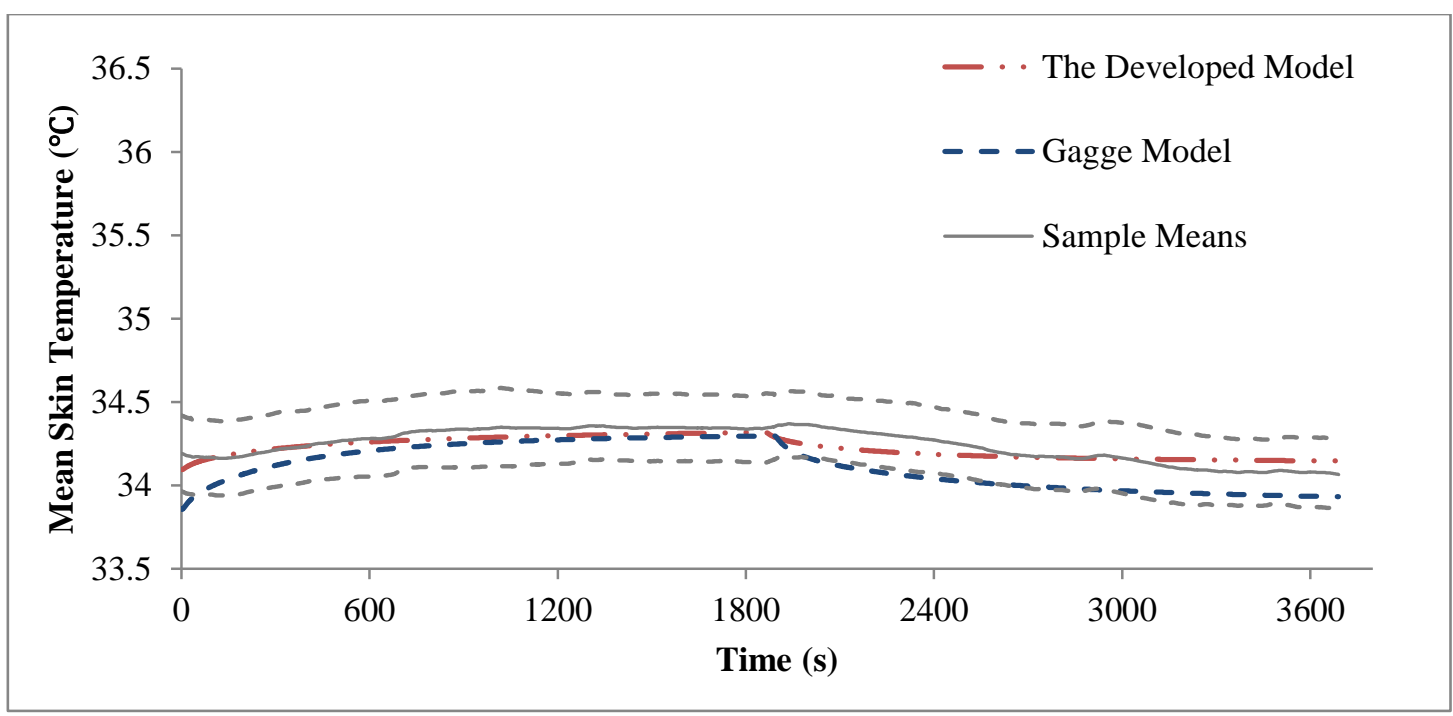

(a) Condition 1

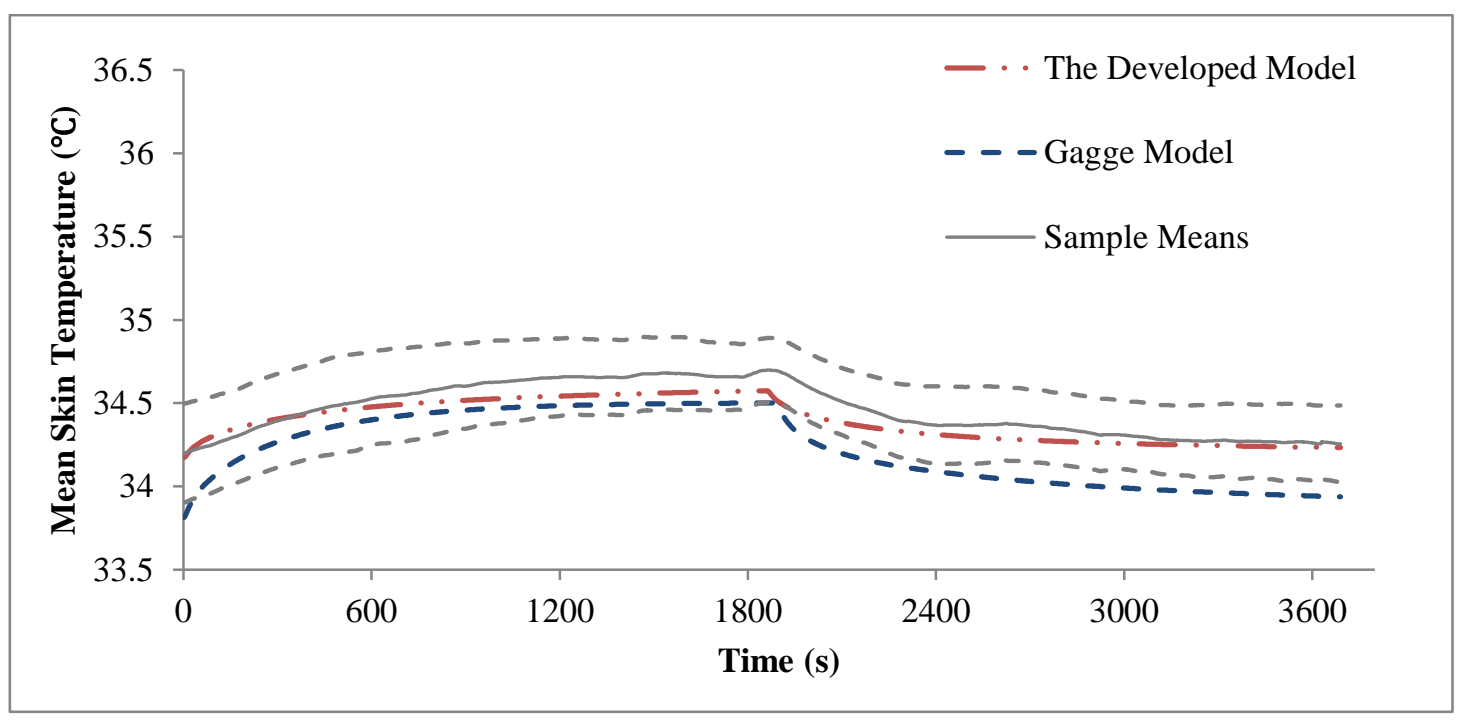

(b) Condition 2

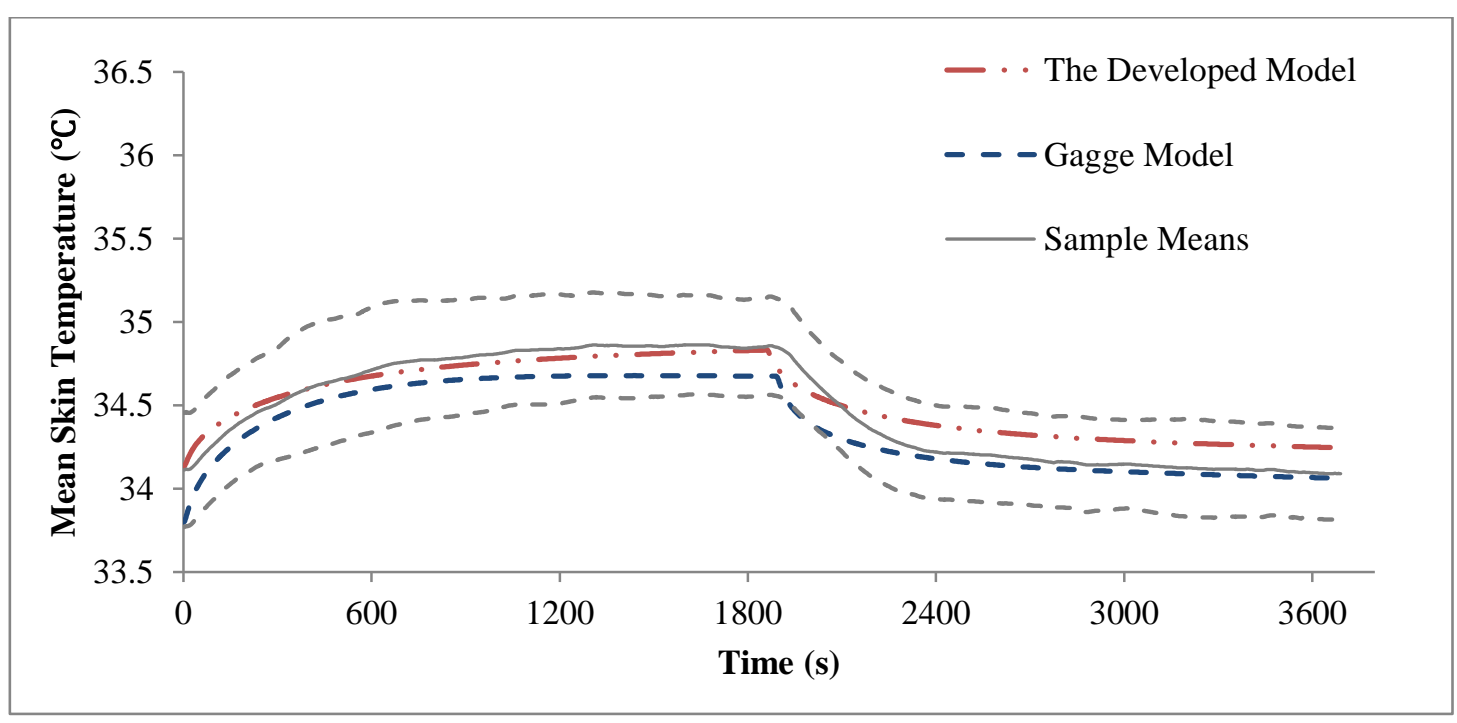

(c) Condition 3 


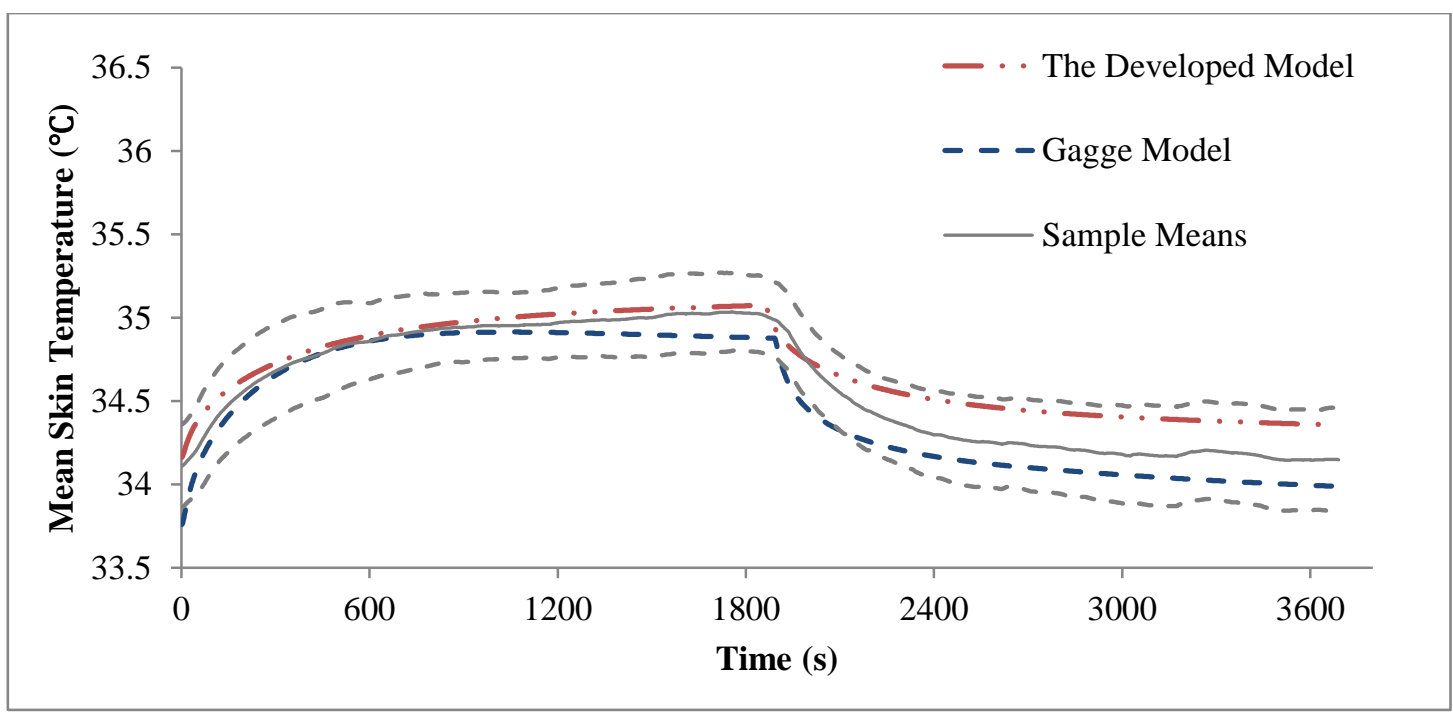

(d) Condition 4

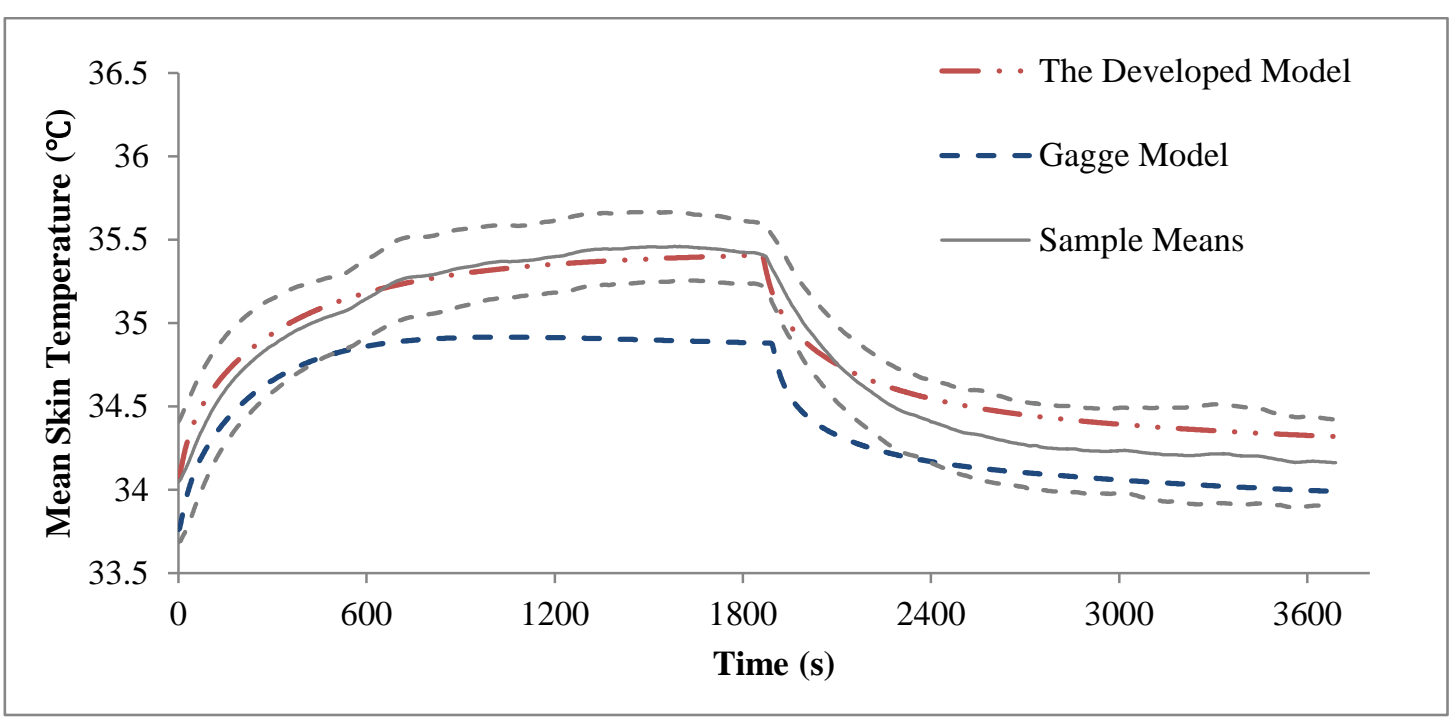

(e) Condition 5

Figure 4. Model validation for Case 1 (male subjects) 


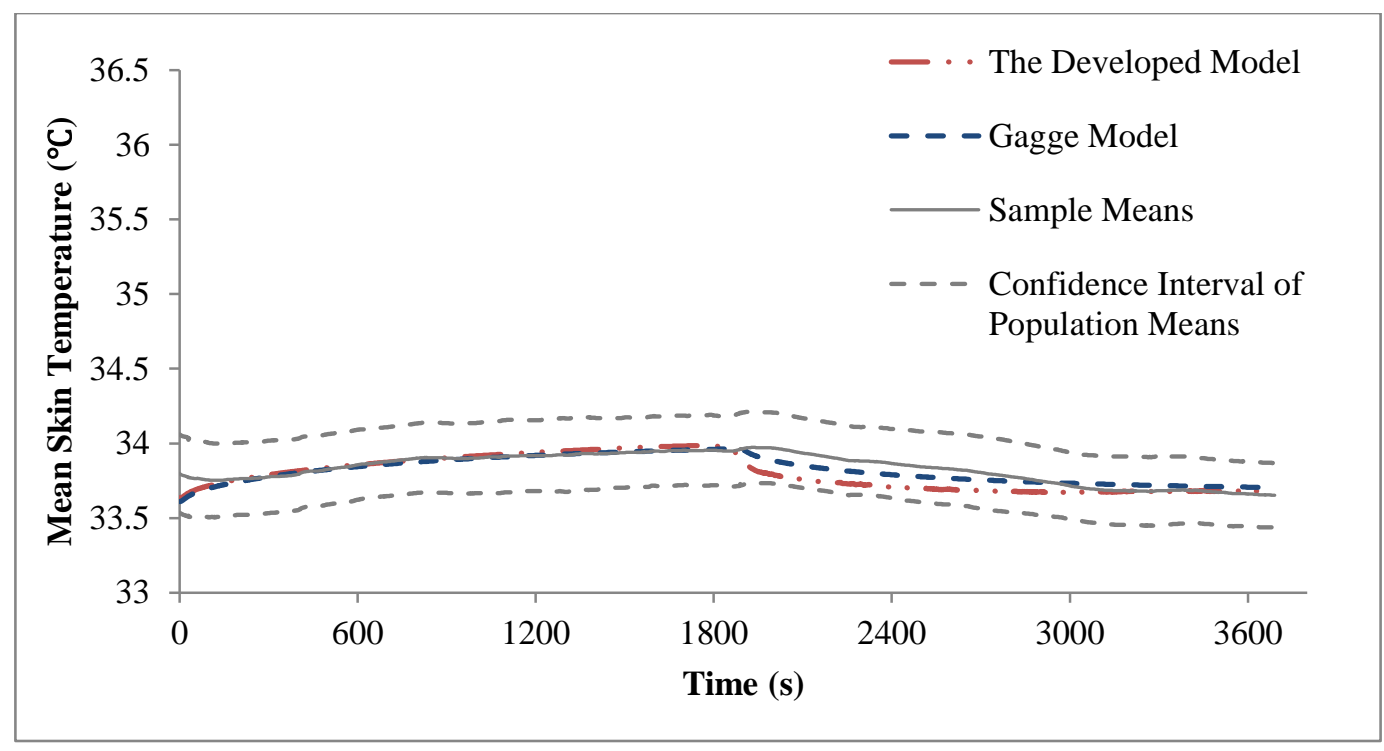

(a) Condition 1

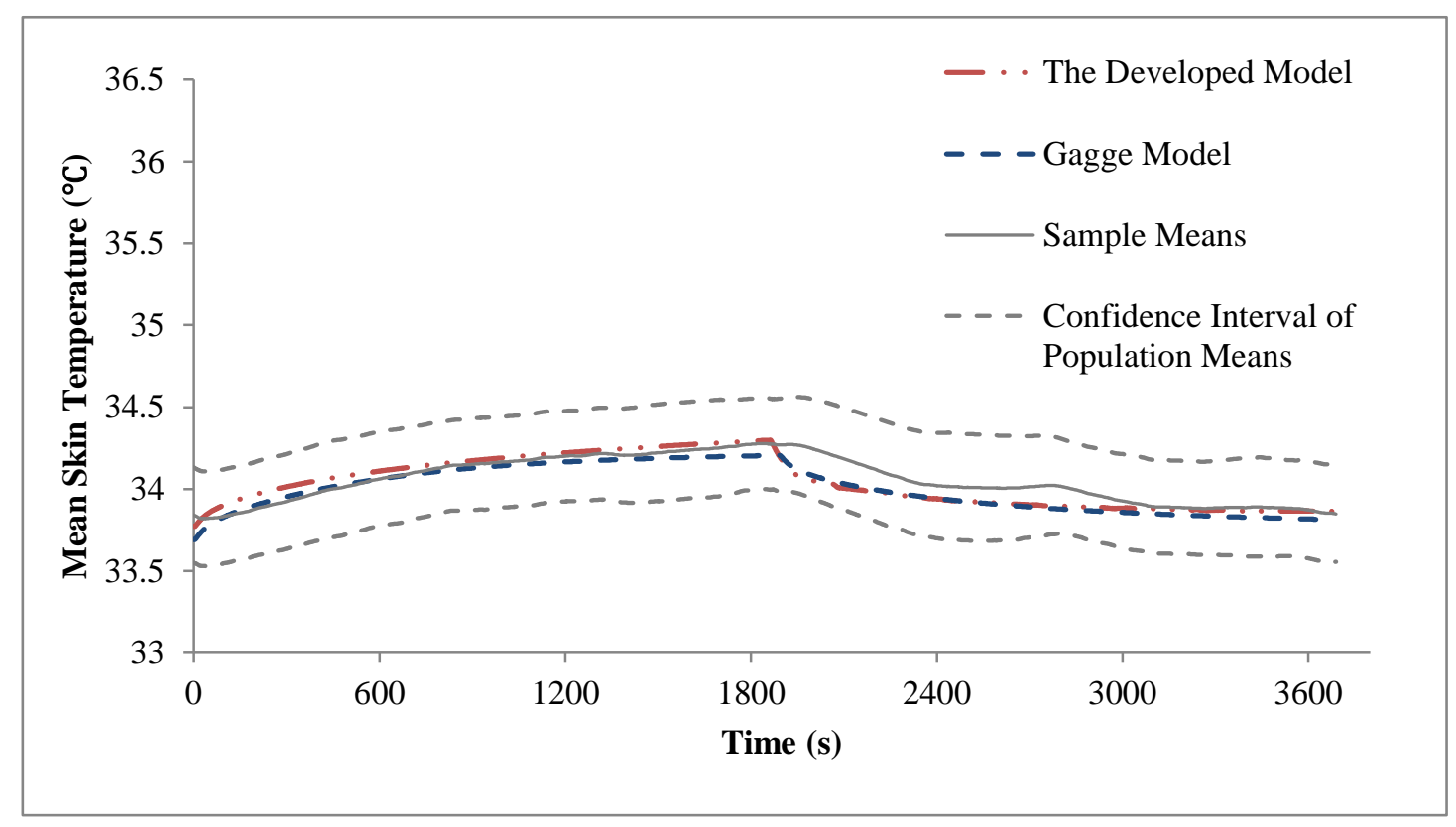

(b) Condition 2 


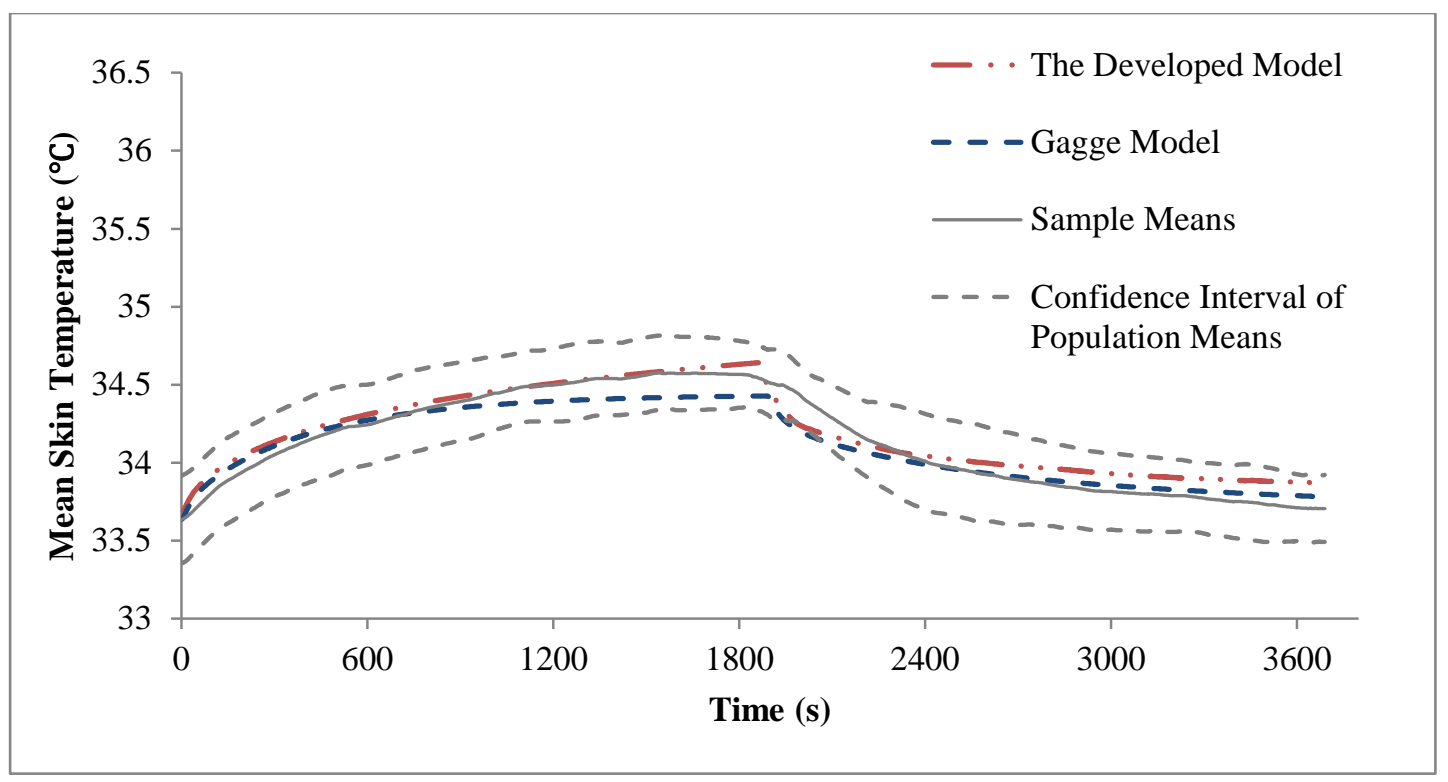

(c) Condition 3

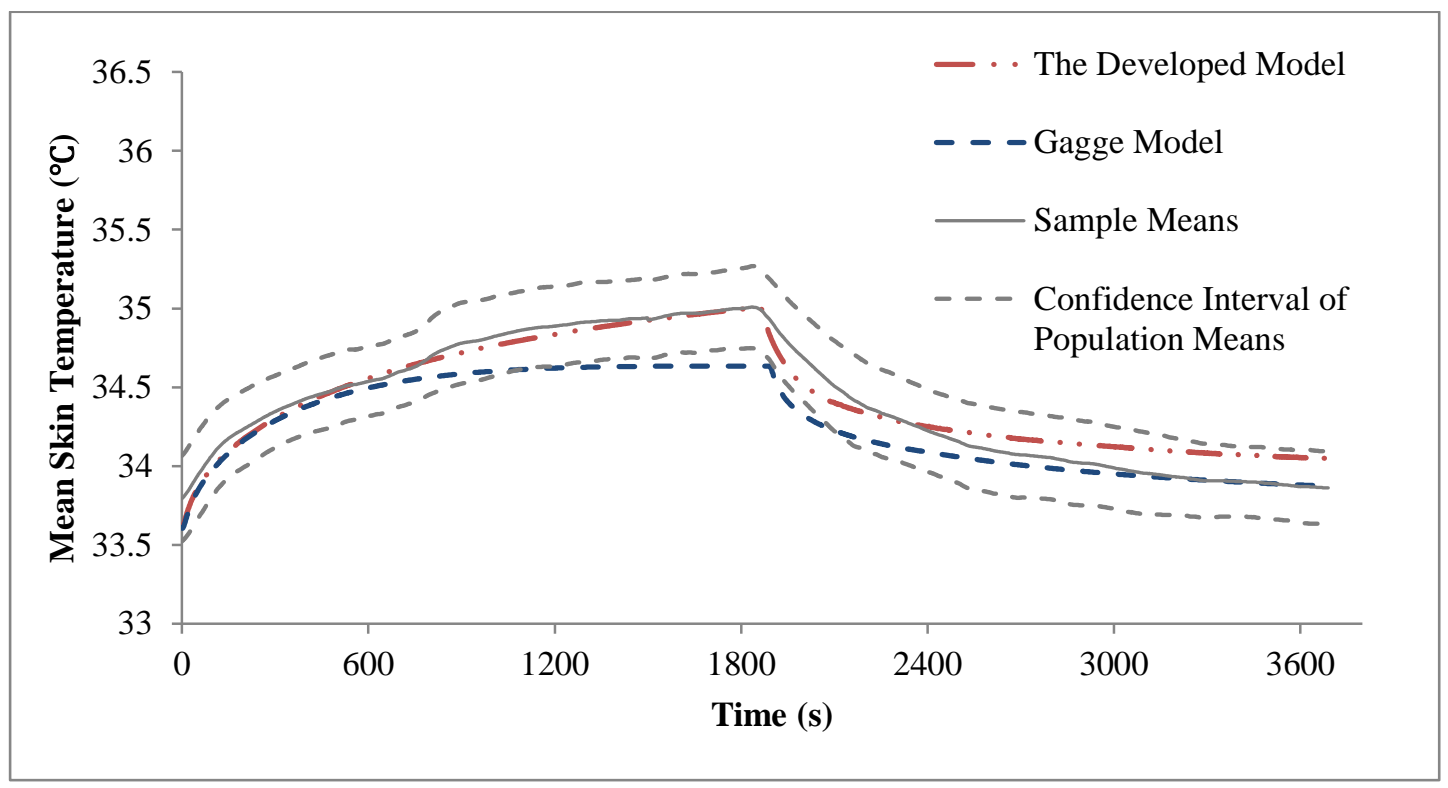

(d) Condition 4 


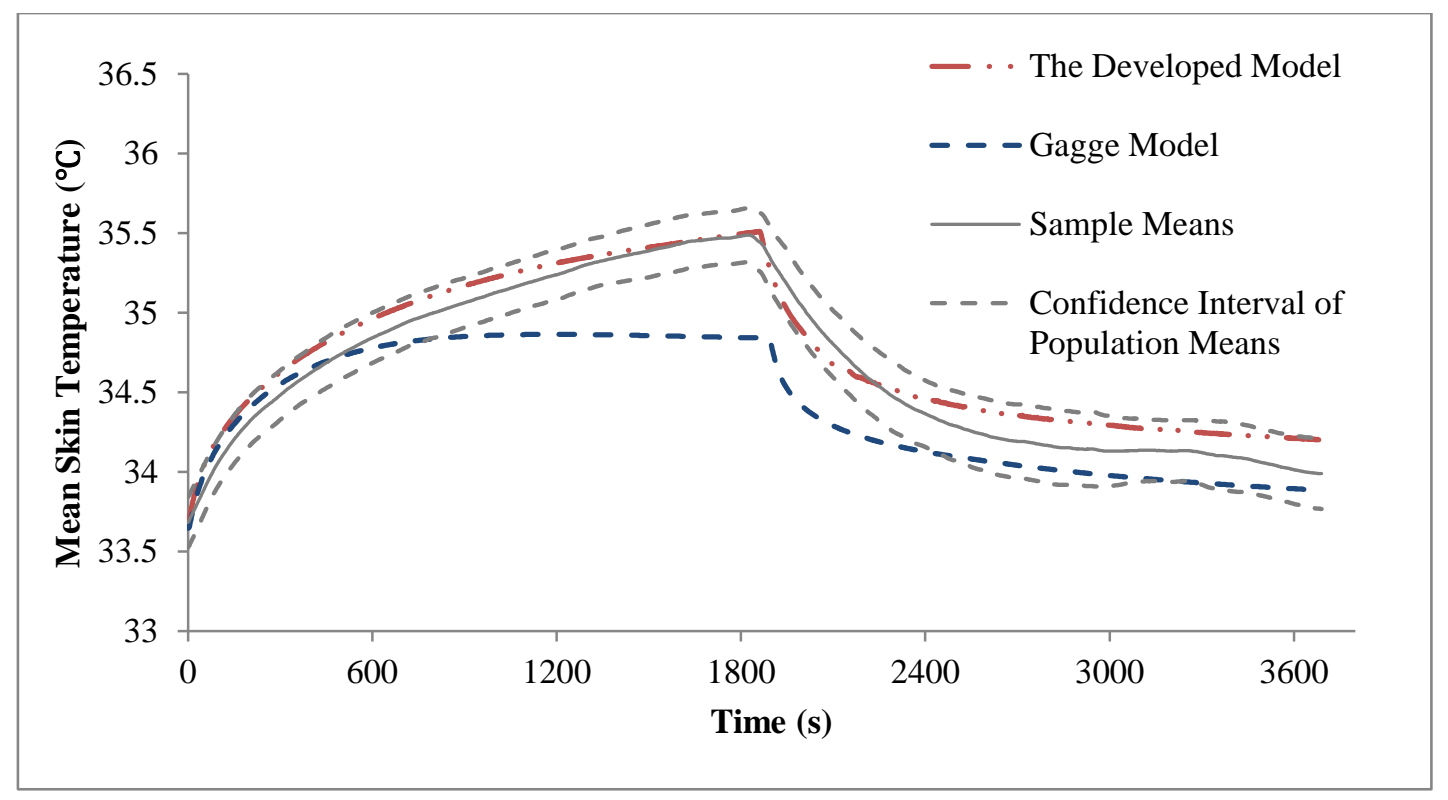

(e) Condition 5

Figure 5. Model validation for Case 1 (female subjects)

\subsection{Case 2}

A further experiment was set up for nude subjects to validate the new simplified model. Ten half-naked healthy male students were randomly recruited as subjects and each participated in one of two condition sets in this experiment. In both conditions, the subjects experienced a temperature step-change process from a neutral environment (Environment I) to a typical warm environment (Environment II) and then stayed in Environment II for a period of 3,600 seconds. The data for the subjects and the thermal conditions in Case 2 are listed in Tables 10 and 11 respectively. Skin temperatures were collected as in Case 1.

Table 10. Subjects' information in Case 2 (mean \pm standard deviation)

Age

Height (m)

Weight $(\mathrm{kg})$

Body fat percentage $(\%)$
$24 \pm 1$

$174 \pm 6$

$60 \pm 7$

$15.8 \pm 2.5$ 
Table 11. Thermal conditions of the experiment in Case 2 (mean \pm standard deviation)

\begin{tabular}{cccccc}
\hline & Case 2 & $\begin{array}{c}\text { Air } \\
\text { Temperatur } \\
\text { e }\left({ }^{\circ} \mathrm{C}\right)\end{array}$ & $\begin{array}{c}\text { Relative } \\
\text { Humidity } \\
(\%)\end{array}$ & $\begin{array}{c}\text { Air Velocity } \\
(\mathrm{m} / \mathrm{s})\end{array}$ & $\begin{array}{c}\text { Globe } \\
\text { Temperature }\left({ }^{\circ} \mathrm{C}\right)\end{array}$ \\
\hline $\begin{array}{c}\text { Condition } \\
1\end{array}$ & Environment I & $28.0 \pm 0.2$ & $61.7 \pm 5.2$ & $0.06 \pm 0.01$ & $28.1 \pm 0.3$ \\
& Environment II & $31.9 \pm 0.1$ & $55.1 \pm 0.3$ & $0.09 \pm 0.02$ & $32.0 \pm 0.1$ \\
$\begin{array}{c}\text { Condition } \\
2\end{array}$ & Environment I & $28.2 \pm 0.1$ & $60.4 \pm 2.8$ & $0.06 \pm 0.01$ & $28.3 \pm 0.2$ \\
& Environment II & $34.7 \pm 0.1$ & $55.8 \pm 0.3$ & $0.18 \pm 0.04$ & $34.7 \pm 0.1$ \\
\hline
\end{tabular}

The predicted values of the new model and experimental results of body skin temperature are shown in Figure 6. For all the conditions, no significant difference was found between the model prediction and the target population. According to the model validation method (Yang et al., 2015a), the accuracy of the model is evaluated as Level I, which means that the new model is statistically accurate to simulate the transient mean skin temperature for the nude population under typical warm conditions. 


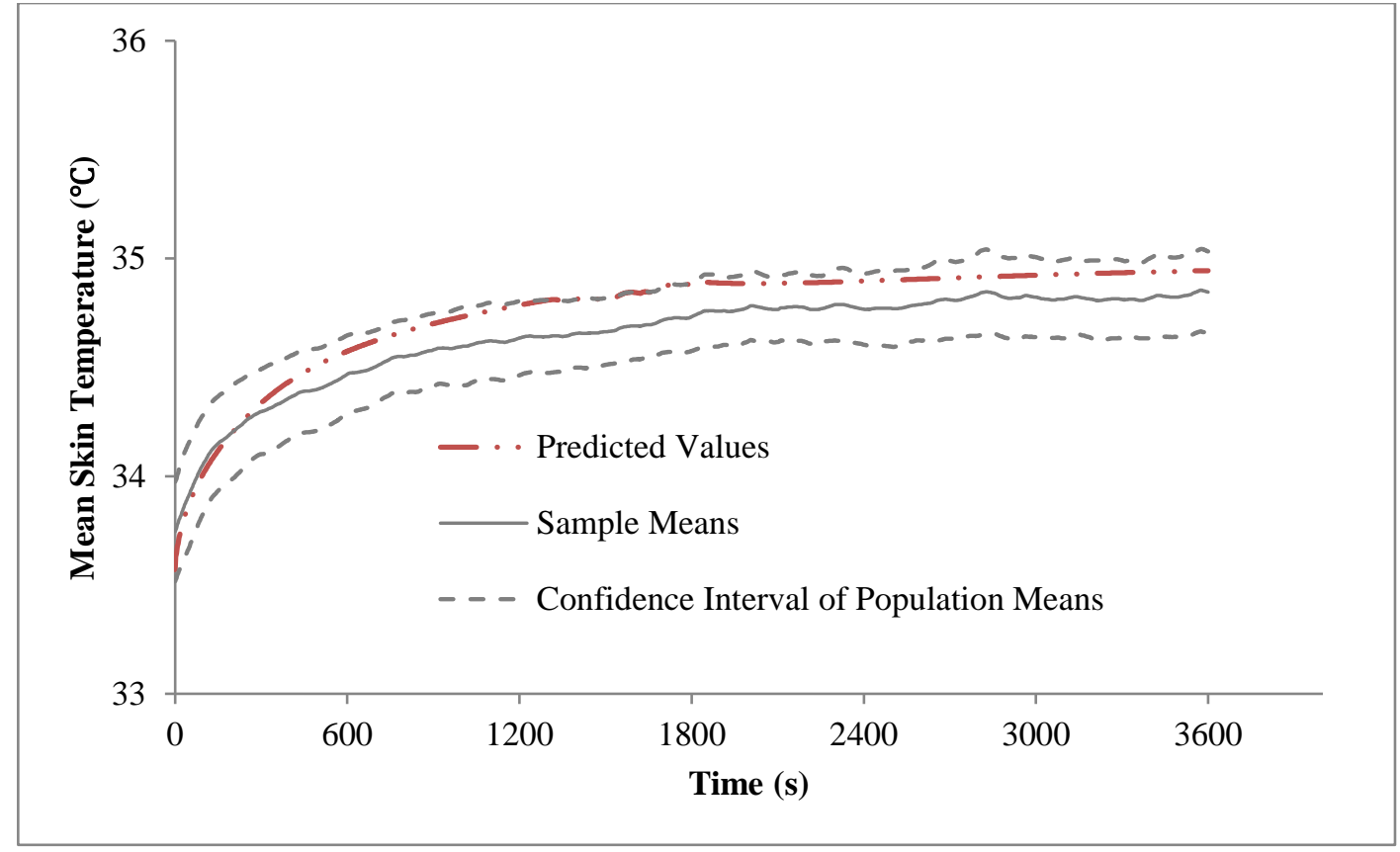

(a) Condition 1

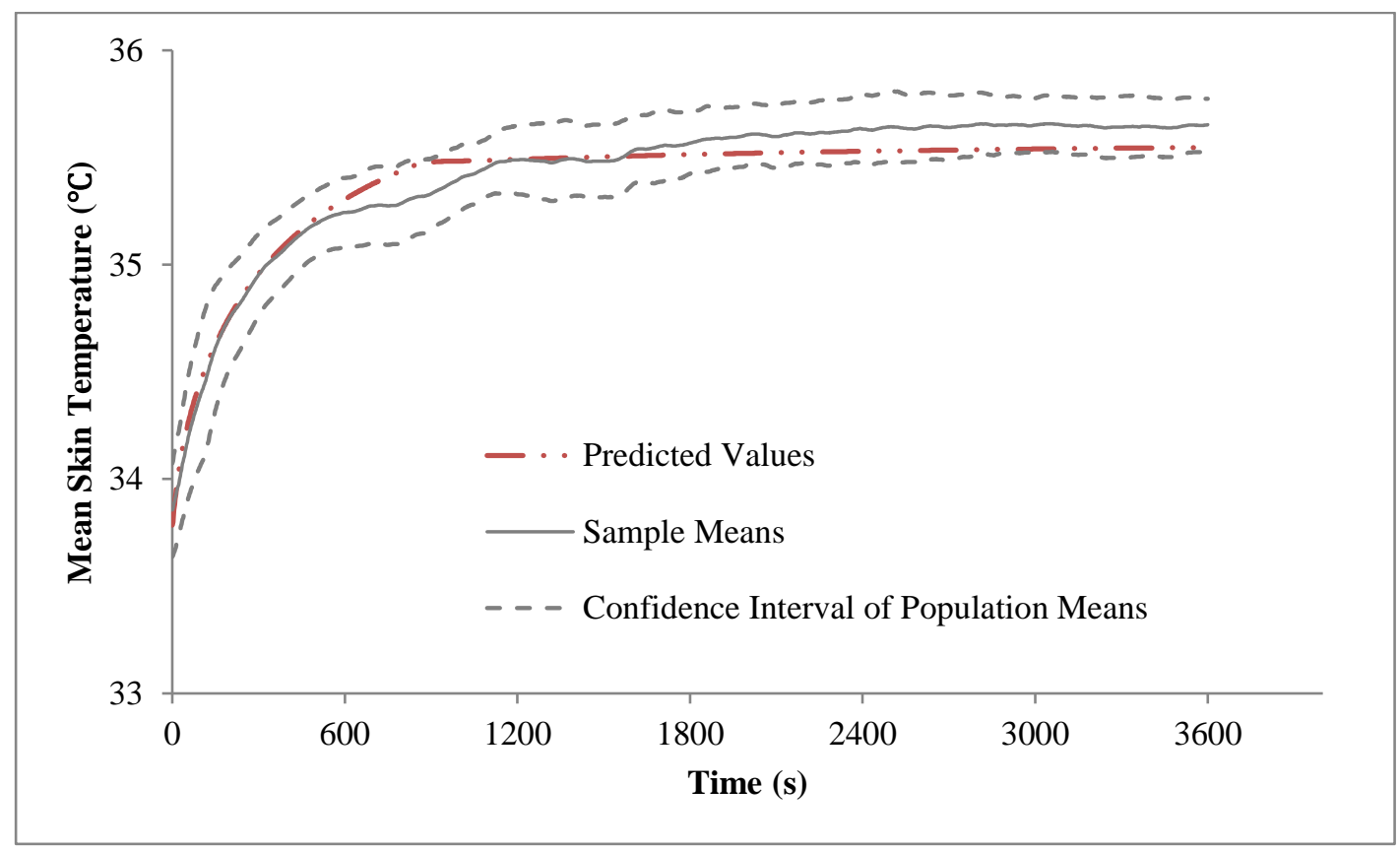

(b) Condition 2

Figure 6. Validation of the Developed Model for Case 2

\subsection{Case 3}

Steady-state experiments were conducted to validate the new model's accuracy in various typical warm environments. The warm environments include the variation of 
temperature, humidity and air velocity. Three series of human exposure experiments with fourteen conditions in total were carried out in a climate chamber. In each series, ten male and ten female healthy subjects were recruited. During the experiment, subjects were required to wear uniform clothing including short-sleeve shirts, shorts and lightweight shoes with an insulation level of $0.26 \mathrm{clo}\left(1 \mathrm{clo}\right.$ equal to $\left.0.155 \mathrm{~m}^{2} \cdot \mathrm{K} / \mathrm{W}\right)$. In each of the conditions, subjects were given sedentary office activities and 120 minutes exposure was provided for subjects to reach a steady state. At the end of the exposure, skin temperatures at 13 locations on the body were recorded as illustrated in Case 1. The data on the subjects and the thermal conditions in Case 3 are listed in Tables 12 and 13 respectively. The default body fat percentages are set as $15 \%$ and $25 \%$ for male and female subjects respectively.

Table 12. Subjects' information in Case 3 (mean \pm standard deviation)

\begin{tabular}{ccccccc}
\hline Series & \multicolumn{2}{c}{ A } & \multicolumn{2}{c}{ B } & \multicolumn{2}{c}{ C } \\
Subjects & Male & Female & Male & Female & Male & Female \\
\hline Age & $24 \pm 1$ & $24 \pm 1$ & $23 \pm 1$ & $24 \pm 1$ & $23 \pm 1$ & $24 \pm 1$ \\
Height (m) & $173 \pm 5$ & $160 \pm 7$ & $175 \pm 5$ & $159 \pm 4$ & $172 \pm 6$ & $160 \pm 3$ \\
Weight (kg) & $61 \pm 4$ & $50 \pm 6$ & $67 \pm 10$ & $46 \pm 4$ & $63 \pm 9$ & $48 \pm 5$ \\
Clothing insulation (clo) & $0.26 \pm 0$ & $0.26 \pm 0$ & $0.26 \pm 0$ & $0.26 \pm 0$ & $0.26 \pm 0$ & $0.26 \pm 0$ \\
Activity level (met) & $1.2 \pm 0$ & $1.2 \pm 0$ & $1.2 \pm 0$ & $1.2 \pm 0$ & $1.2 \pm 0$ & $1.2 \pm 0$ \\
\hline
\end{tabular}

Table 13. Thermal conditions of the experiment in Case 3 (mean \pm standard deviation)

Case 3

$$
\text { Ambient Temperature }\left({ }^{\circ} \mathrm{C}\right) \quad \text { Relative } \quad \operatorname{Velocity}(\mathrm{m} / \mathrm{s}) \quad \text { Black-bulb }
$$

Series Conditions

$\begin{array}{llllll}\text { A } & 1 & 26.9 \pm 0.2 & 54 \pm 4 & 0.11 \pm 0.02 & 26.6 \pm 0.1\end{array}$




\begin{tabular}{|c|c|c|c|c|c|}
\hline & 2 & $28.9 \pm 0.2$ & $55 \pm 7$ & $0.11 \pm 0.04$ & $28.5 \pm 0.2$ \\
\hline & 3 & $31.0 \pm 0.2$ & $51 \pm 7$ & $0.14 \pm 0.04$ & $30.4 \pm 0.1$ \\
\hline & 4 & $32.9 \pm 0.2$ & $54 \pm 5$ & $0.12 \pm 0.02$ & $32.3 \pm 0.1$ \\
\hline \multirow{6}{*}{ B } & 1 & $25.6 \pm 0.1$ & $41 \pm 1$ & $0.08 \pm 0.05$ & $25.6 \pm 0.1$ \\
\hline & 2 & $25.9 \pm 0.1$ & $60 \pm 1$ & $0.1 \pm 0.06$ & $25.6 \pm 0.1$ \\
\hline & 3 & $28.0 \pm 0.1$ & $40 \pm 2$ & $0.07 \pm 0.01$ & $27.6 \pm 0.1$ \\
\hline & 4 & $27.9 \pm 0.1$ & $60 \pm 1$ & $0.09 \pm 0.03$ & $27.6 \pm 0.2$ \\
\hline & 5 & $29.8 \pm 0.1$ & $42 \pm 2$ & $0.1 \pm 0.02$ & $29.4 \pm 0.2$ \\
\hline & 6 & $29.9 \pm 0.1$ & $60 \pm 1$ & $0.09 \pm 0.03$ & $29.4 \pm 0.1$ \\
\hline \multirow{4}{*}{ C } & 1 & $28.0 \pm 0.1$ & $90 \pm 1$ & $0.6 \pm 0.03$ & $28.0 \pm 0.1$ \\
\hline & 2 & $28.1 \pm 0.2$ & $90 \pm 1$ & $0.79 \pm 0.04$ & $28.0 \pm 0.2$ \\
\hline & 3 & $30.0 \pm 0.2$ & $80 \pm 1$ & $0.81 \pm 0.04$ & $29.8 \pm 0.2$ \\
\hline & 4 & $32.0 \pm 0.2$ & $80 \pm 1$ & $0.79 \pm 0.03$ & $31.9 \pm 0.2$ \\
\hline
\end{tabular}

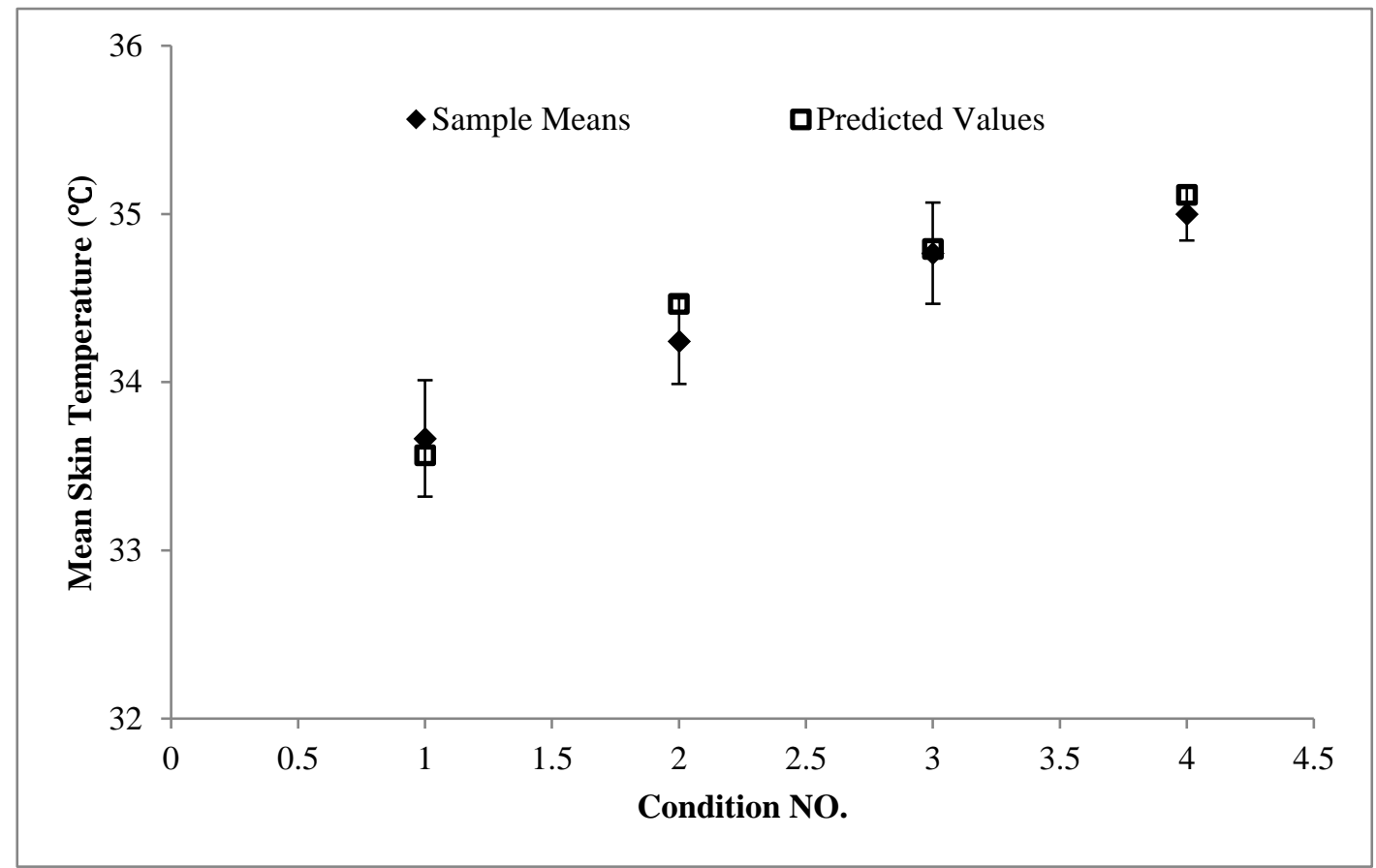

(a) Series A 


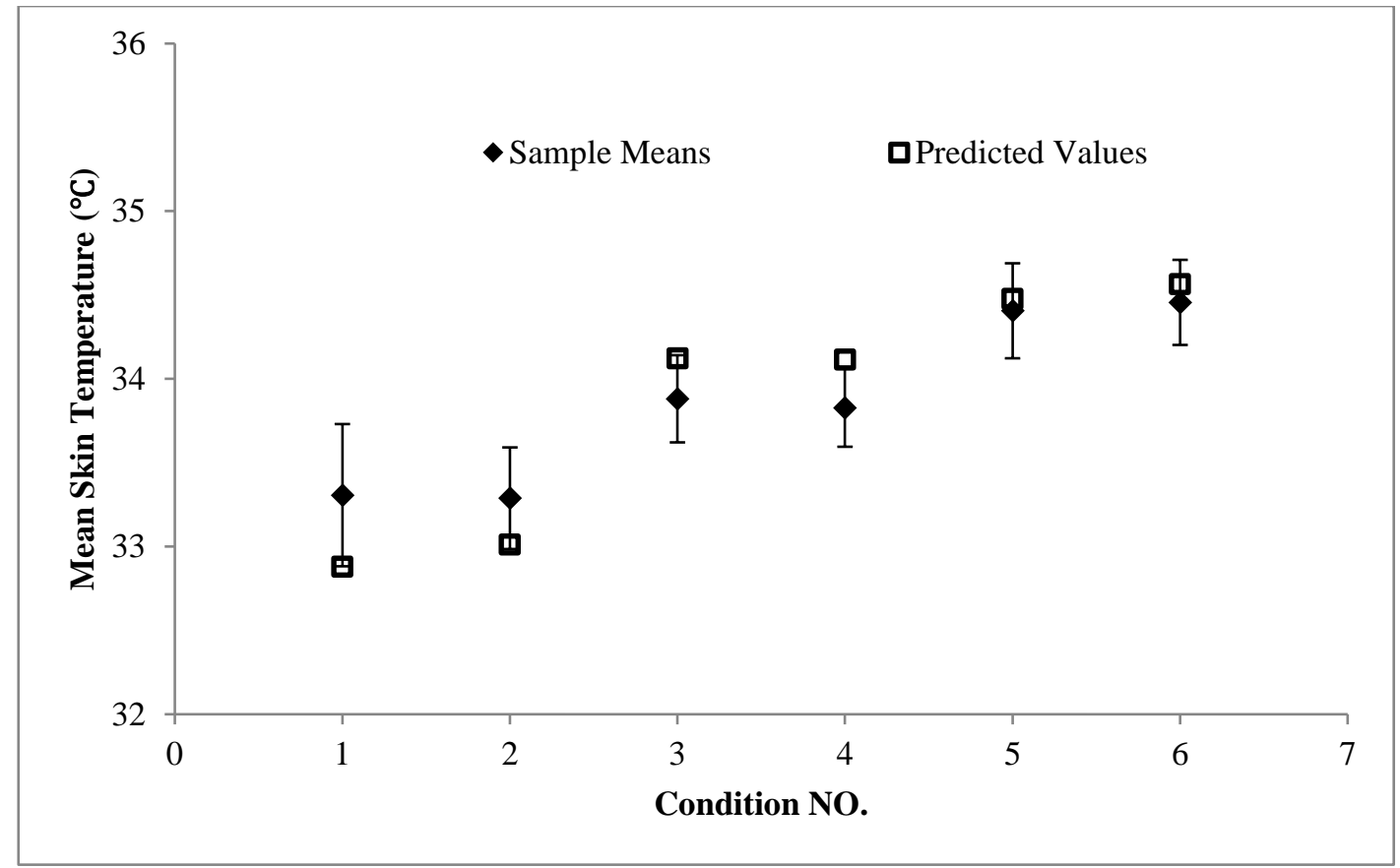

(b) Series B

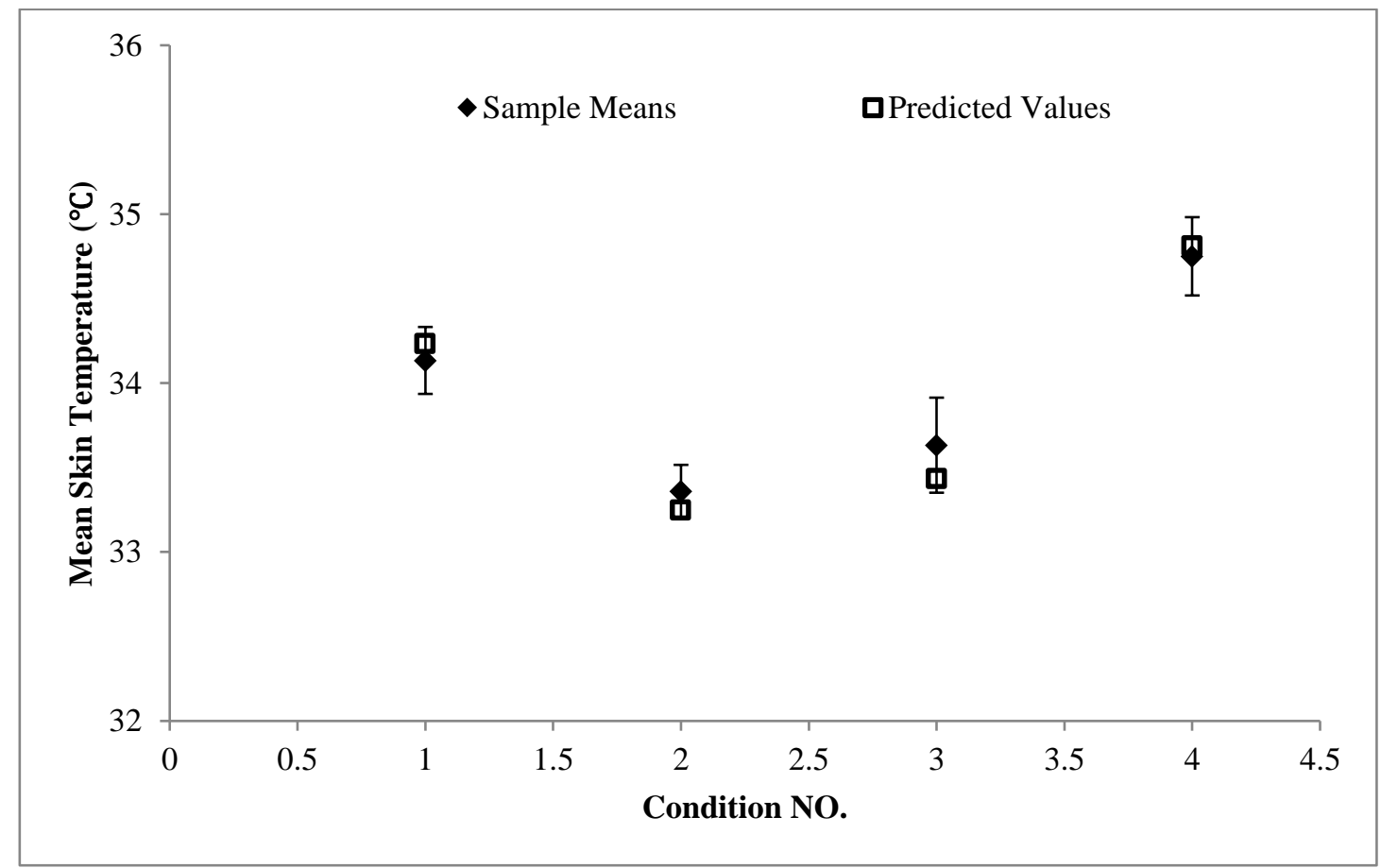

(c) Series C

Figure 7. Validation of the Developed Model for Case 3 (male subjects)

(The error bars represent the 95\% confidence interval for the population means) 


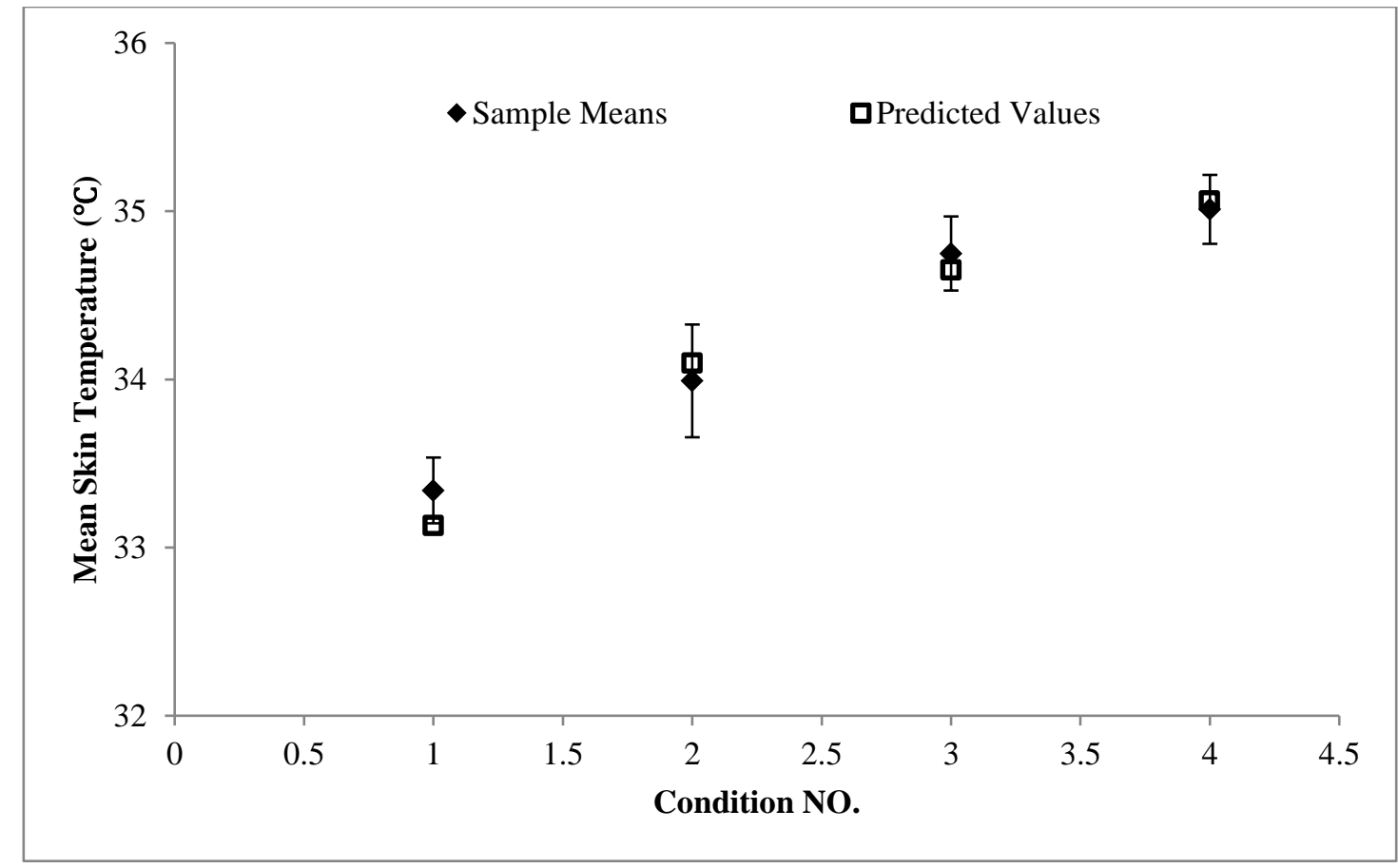

(a) Series A

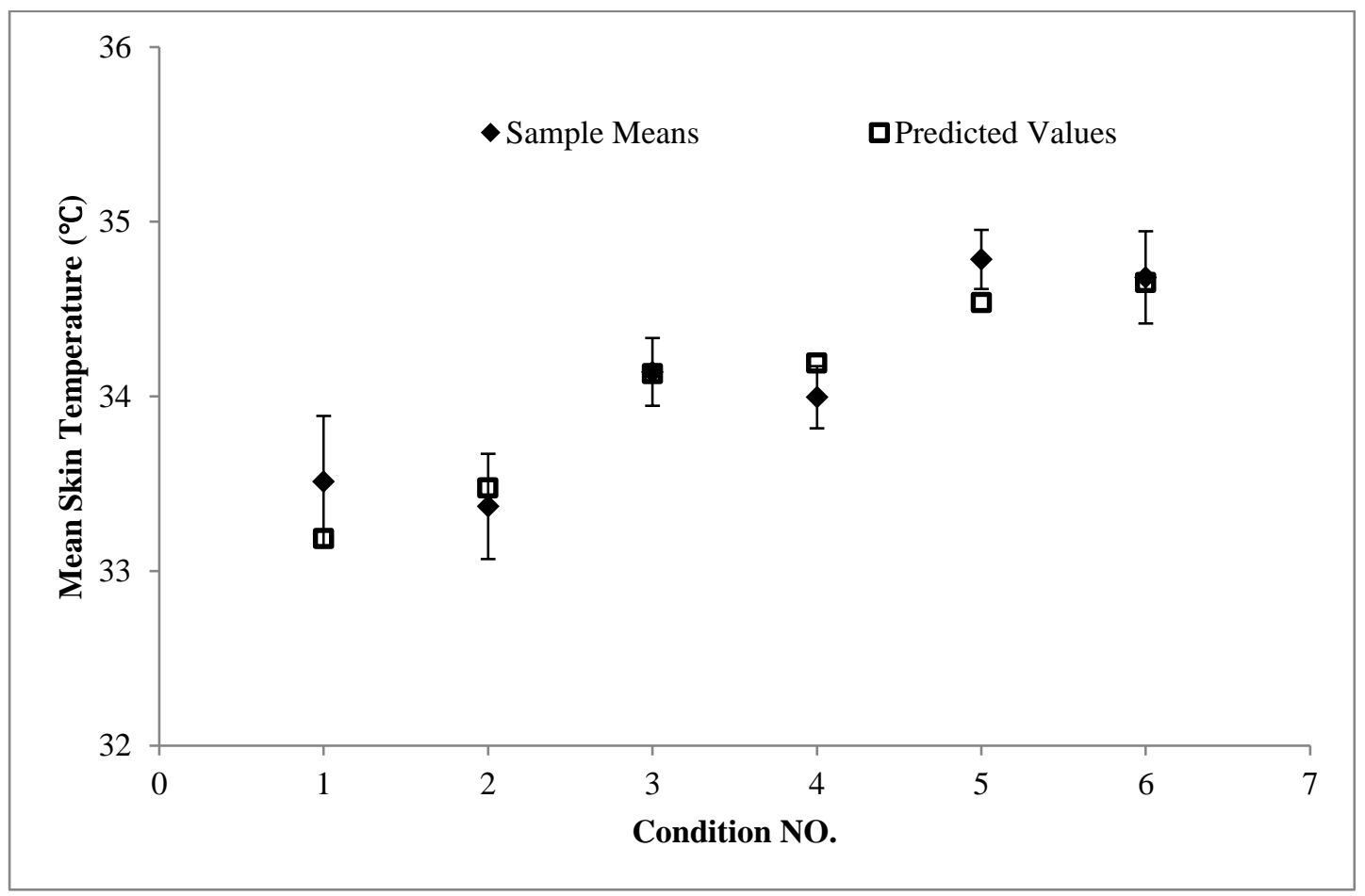

(b) Series B 


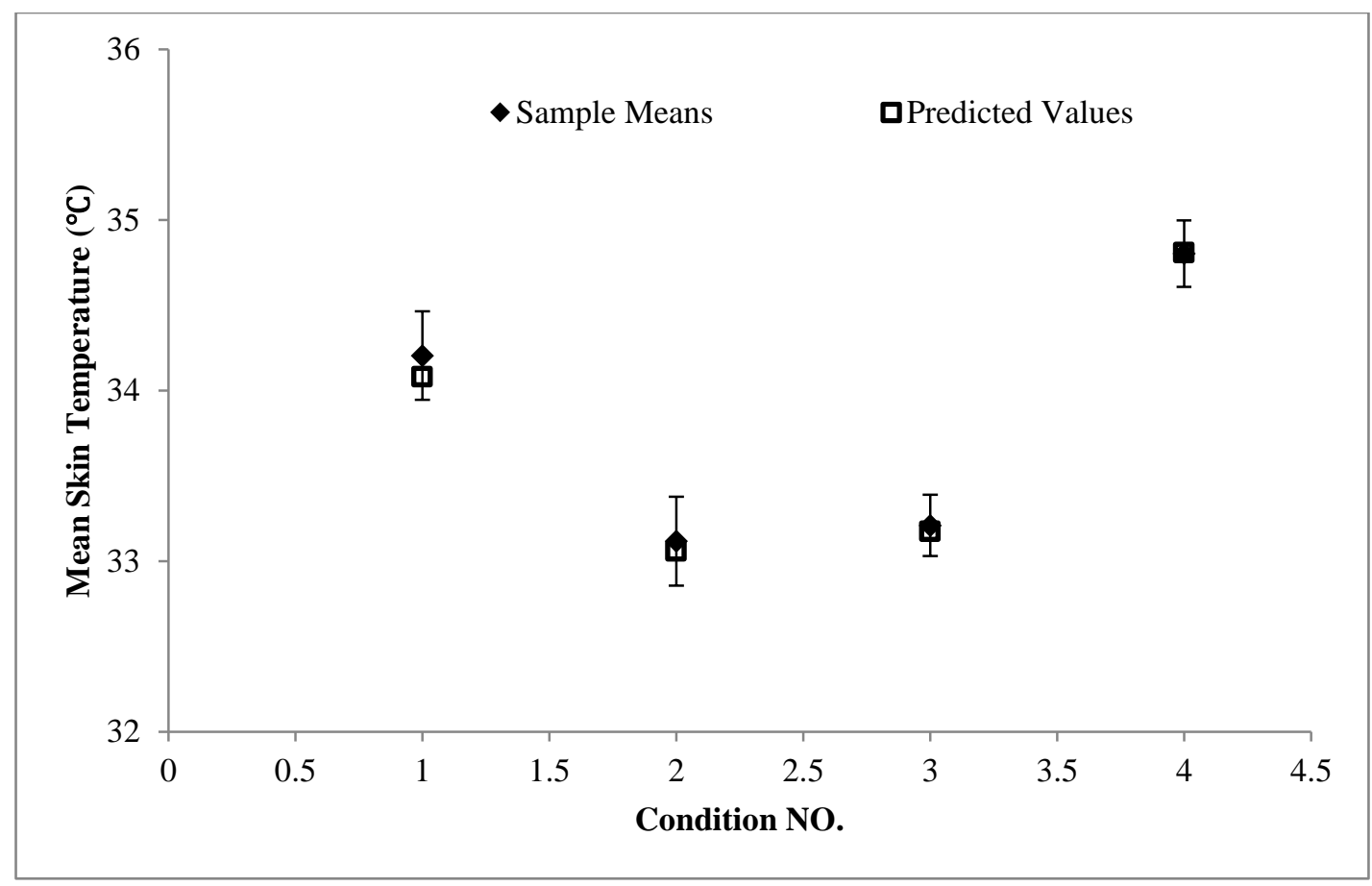

(c) Series C

Figure 8. Validation of the Developed Model for Case 3 (female subjects)

(The error bars represent the 95\% confidence interval for the population means)

The predicted values of the new model and experimental results of the body skin temperature under different conditions are shown in Figure 7 and Figure 8 for male and female subjects respectively. The skin temperature for both males and females can be accurately predicted by the developed model. The performance of the new model in the steady state condition is evaluated as Level $\mathrm{I}$.

\section{Discussion}

A thermoregulation model of the human body has been presented. The new model is simplified compared to most existing models (e.g. (Fiala et al., 2001; Huizenga et al., 2001; Wan and Fan, 2008) etc.). Nevertheless, the model is statistically accurate in estimating the transient skin temperature of the human body as discussed in the next section. The model has been validated by comparing its simulation with experimental results from responses by a total of 400 subjects under typical warm conditions, as 
shown in Table 14. The advantage of this simplified model is that it can be more practical in application and yet further optimization of the empirical parameters can be more easily achieved.

Table 14. Accuracy level in Case validation

\begin{tabular}{ccc}
\hline Case study & Working conditions & The accuracy of the model \\
\hline Case 1 & $\begin{array}{c}\text { Transient response for subjects } \\
\text { with light clothing }\end{array}$ & Level I \\
\hline Case 2 & $\begin{array}{c}\text { Transient response for the nude } \\
\text { population }\end{array}$ & Level I \\
\hline Case 3 & Steady state & Level I \\
\hline
\end{tabular}

In contrast with the existing models, the major contribution of this newly developed model is to point out three questions neglected in thermoregulation modelling and optimize them. They involve a) the evaporation efficiency of regulatory sweat; b) the effect of body surface area on thermoregulatory calculations; c) the gender difference. The developed model establishes its advantages over current models as shown in Table 15.

Table 15. Advantages and development of the new model over existing models

\begin{tabular}{ll}
\hline \multicolumn{1}{c}{ Advantages } & \multicolumn{1}{c}{ Development compared with the existing models } \\
\hline $\begin{array}{c}\text { Differences between } \\
\text { races }\end{array}$ & $\begin{array}{l}\text { 1) Physical parameters of the physical abstract model. } \\
\text { 2) Metabolic heat production in the controlled system. } \\
\text { 3) Parameter selection and optimization in the controlling system. }\end{array}$ \\
\hline $\begin{array}{c}\text { Differences between } \\
\text { individuals }\end{array}$ & $\begin{array}{l}\text { 1) Height, weight, body fat rate. } \\
\text { 2) Age Factor. }\end{array}$ \\
& 3) Gender factor. \\
\hline Simplicity and accuracy & 1) Simplicity: physical structure, the input parameters. \\
& 2) Accuracy: model validation, accuracy level. \\
\hline
\end{tabular}




\subsection{Evaporation efficiency of regulatory sweating}

In the new model, the calculation of heat loss by regulatory sweating is optimized based on the empirical formula in Stolwijk (1971). The value of $E_{s w}$ calculated from the new model is obviously lower than that obtained from the model in Stolwijk (1971) under the same conditions. The original empirical formula for calculating $E_{s w}$ (Stolwijk, 1971) was based on a common assumption that all the sweating can be evaporated directly. However, the reality is that considerable sweating will adhere to the body surface, clothing or drop down from the body rather than evaporating instantly as heat loss. Thus, the original calculation for $E_{s w}$ overestimates the evaporation heat loss and modified empirical formulas considering the 'evaporation efficiency' are employed as Equation 40 and Equation 41. In order to illustrate the optimization of evaporation by sweating, the study applied the original and modified equations for $E_{s w}$ respectively to simulate male subjects' skin temperature in the thermal process of Condition 5 in Case 1, the results for the initial 1,800 seconds are shown in Figure 9. It is obvious that when applying the original calculation for $E_{s w}$, the predicted skin temperature is significantly lower than the measured value, which is the result of the overestimation

of $E_{s w}$. This optimization of $E_{s w}$ has also been validated in all the high temperature conditions in our experiments. As the assumption that the sweating can be evaporated away completely is quite common in the existing models (e.g. (Gagge et al., 1971; Munir et al., 2009; Tanabe et al., 2002)), the question of sweating evaporation efficiency should be worthy of attention in further models. 


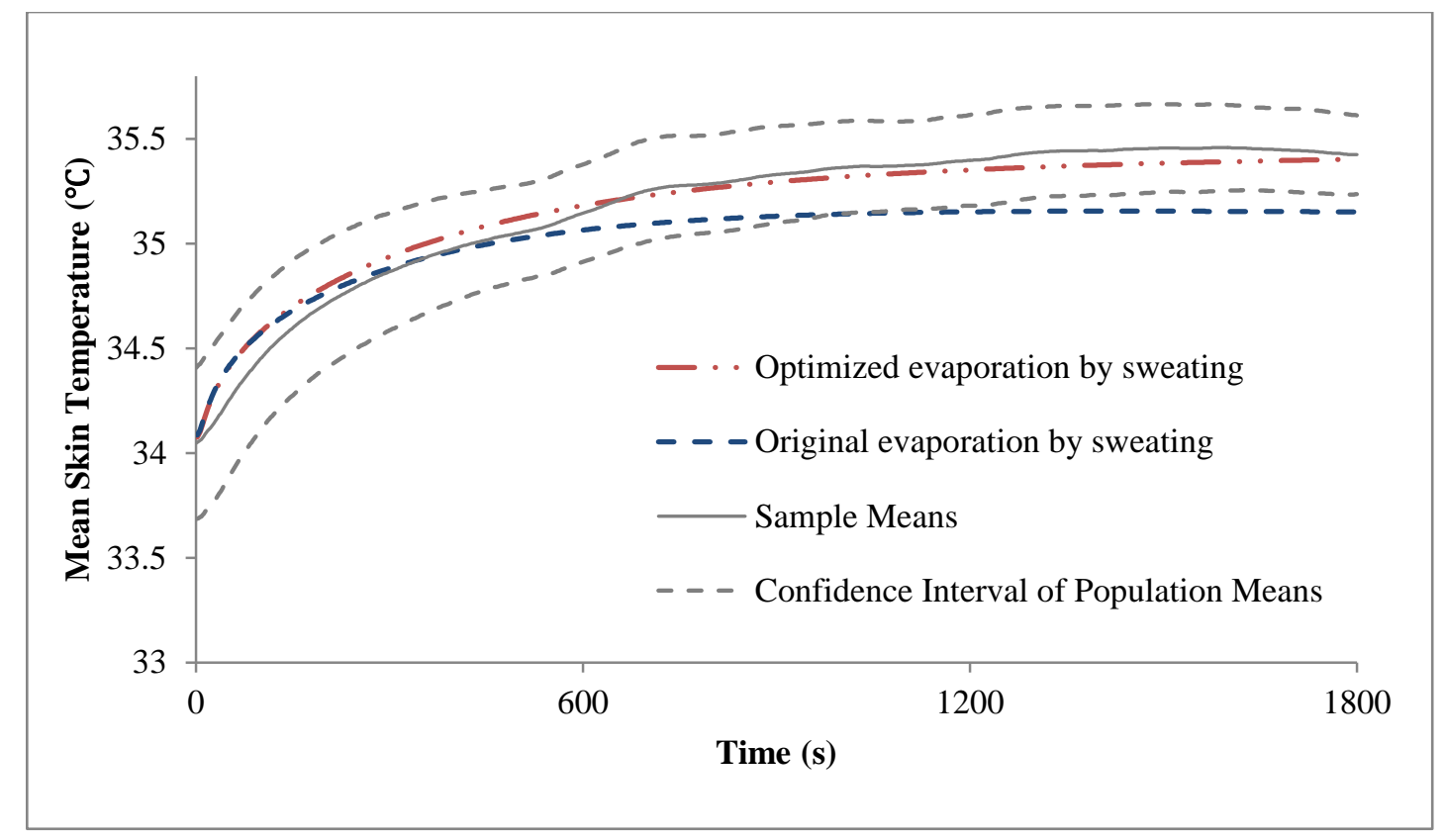

Figure 9. Example to illustrate the optimization of evaporation by sweating

\subsection{Effect of body surface area on thermoregulatory calculation}

The body surface area $(A)$ decides the heat transfer at the skin surface thereby further influencing the body temperature. However, in most existing models (e.g. (Gagge et al., 1971; Stolwijk, 1971; Tanabe et al., 2002)), the effect of $A$ is ignored when calculating the value of total heat loss by regulatory sweating or total skin blood flow, both of which should be theoretically proportional to $A$. As a modification, the new model introduces the variable $\boldsymbol{A}$ into the formula when estimating the total heat loss by regulatory sweating and total skin blood flow. Figure 10 shows the results of the model with (Equation 36 and Equation 43) or without (Equation 44 and Equation 45) consideration of $A$ respectively when predicting the first 1,800 seconds of Condition 5 in Case 1 for females. According to the model evaluation method, the model's performance is improved from Level II to Level I by introducing $A$ into the calculation of total heat loss by regulatory sweating and total skin blood flow. The effect of $A$ on the simulation results is usually insignificant for populations with similar physiques; however, when 
populations have significantly different values of $A$, e.g. the value is calculated as $1.6 \mathrm{~m}^{2}$ for Chinese females compared with the $1.89 \mathrm{~m}^{2}$ (Stolwijk, 1971) for an American or European 'standard man', the effect of $A$ should not be ignored. This optimization, based on the effect of $A$, takes into account the different physiques of populations, which makes the model more reasonable and reliable.

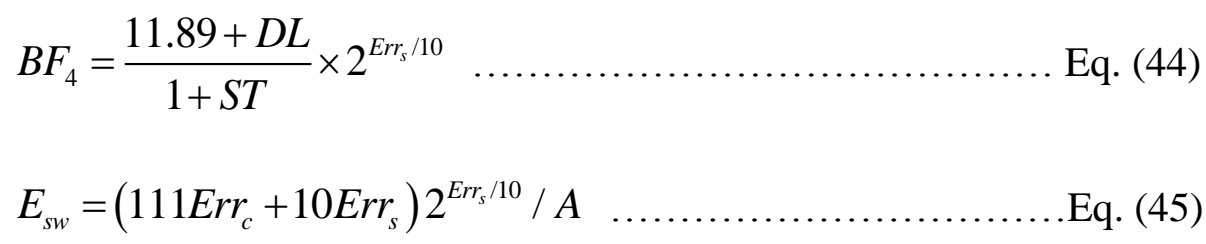

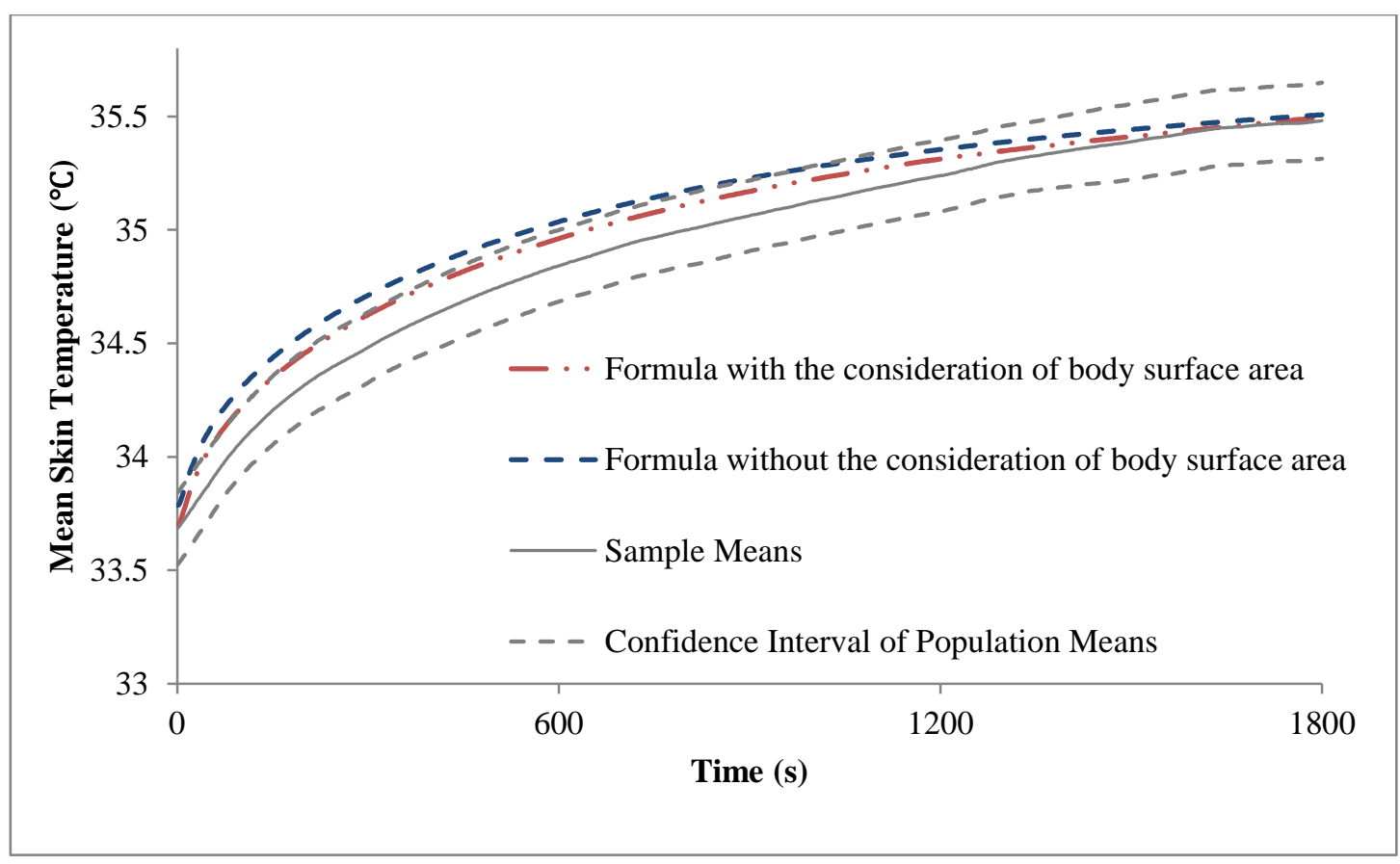

Figure 10. Example to illustrate the effect of body surface area on thermoregulatory calculations

\subsection{Gender difference}

In the new model, the difference in gender is introduced into calculations of basal metabolic rate, fat percentage, body surface and evaporation heat loss etc., all of which will affect in the final temperature distribution of the body. The experiment in Case 1 shows that under the same thermal conditions (e.g. Condition 5), the characteristics of 
temperature regulation are significantly different for male and female subjects. As shown in Figure 11, these experimental results can be well illustrated by the new model with the consideration of gender difference, which is an improvement on the existing models.

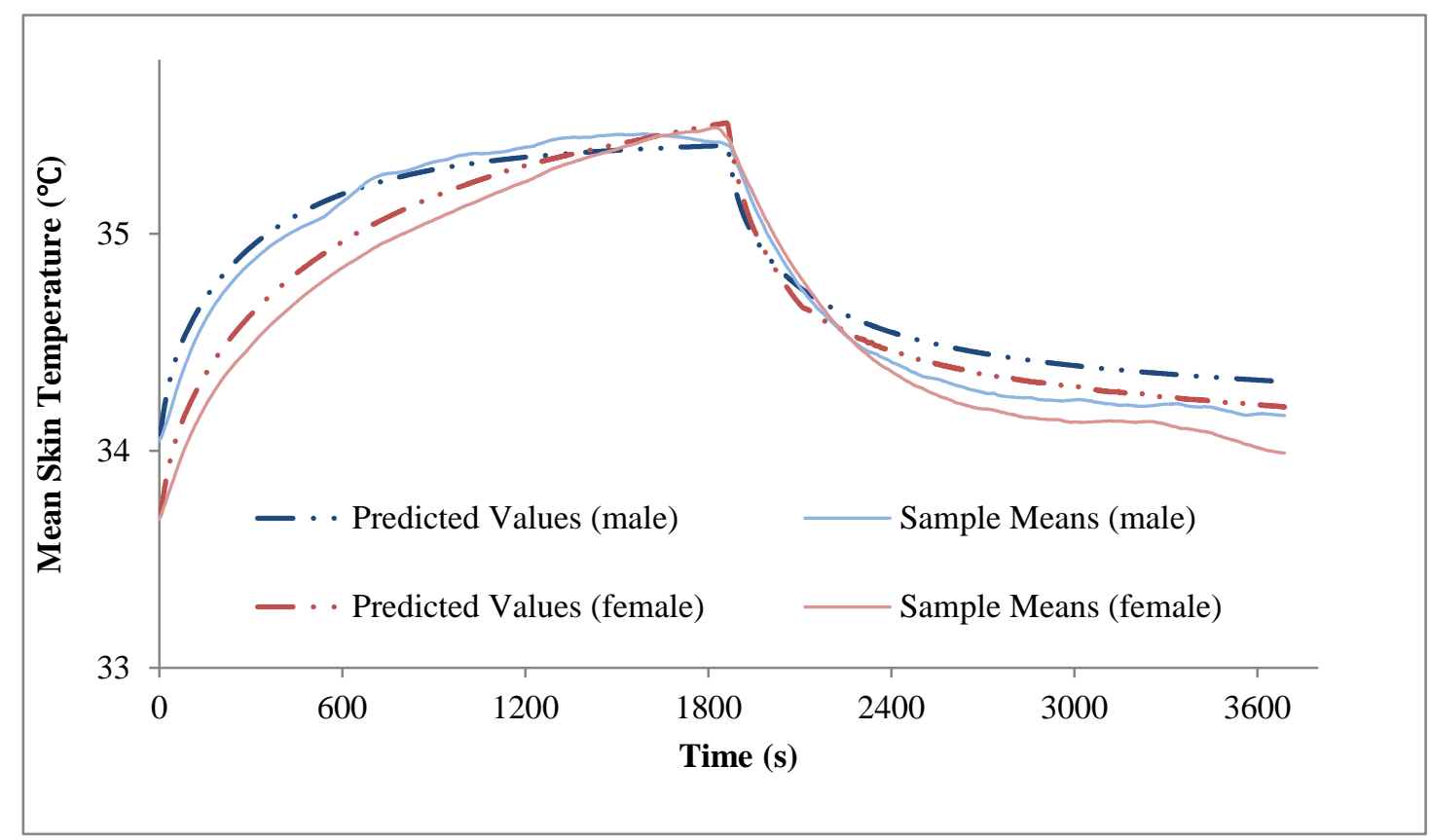

Figure 11. Example to illustrate the gender difference

The differences in the thermal responses of males and females have been noticed by many studies because of their different physiological characteristics. The discriminations have been made in this study such as the calculation of body surface area "A" and the mean basal metabolic rate. Besides, the gender factor has a direct influence on the physical model of the human body including the height, weight and body fat percentage which cannot be avoided. So this study tries to solve the prediction deviation caused by gender by deducing a separate formula for males and females, together with certain actual measured data for the two groups.

\section{Conclusions}

This paper presents a simplified thermoregulation model of the human body. The new 
model is statistically accurate in predicting mean skin temperature in warm environments and has been verified by three sets of experiments including 21 typical conditions with 400 subjects in total. This model consists of three parts: i) the physical model, which is an abstraction of the real body; ii) the controlled system, which is used to simulate the heat transfer of the body and environment; and iii) the controlling system, which describes the thermoregulatory control mechanisms of the human body.

This newly-developed model has been used to analyse the mean skin temperate based on the data from the group of subjects and reveals three key phenomena which are normally ignored in the existing models: a) the role played by the evaporation efficiency of regulatory sweating; b) the proportional relation of total skin blood flow and total heat loss by regulatory sweating against body surface area and c) there are discrepancies in the mean skin temperature between the genders. The newly-developed model has been subject to experimental validation which supports its optimizational modifications that lead to advantages in application accuracy compared to current mainstream models. Meanwhile, the introduction of a cylinder model and the development of control plates make it more convenient in application compared to other human thermal prediction models.

This model can be widely applied in the field of thermal comfort study, in particular for the prediction of transient skin temperature in different thermal processes. It is applicable for the iterative calculation of environmental and physiological parameters in the dynamic thermal environments in terms of different times and spaces.

\section{ACKNOWLEDGEMENT}

The authors would like to thank the Natural Science foundation (No. 51561135002) and 111 Project (No. B13041) for their financial support on the research. Yu Yang and 
Yongqiang Li would like to thank the China Scholarship Council for the sponsorship for a one-year academic visiting study at the University of Reading.

\section{REFERENCES}

Andrew Thatcher, P.H.P.Y., 2016. Human factors for a sustainable future. Applied Ergonomics 57, 1-7.

Arezes, P., Neves, M.M., Teixeira, S., Leão, C.P., Cunha, J., 2013. Testing thermal comfort of trekking boots: An objective and subjective evaluation. Applied ergonomics 44, 557-565.

ASHRAE-55, 2004. Thermal environmental conditions for human occupancy. American Society of Heating, Refrigerating and Air-conditioning Engineers.

Cheng, Y., Niu, J., Gao, N., 2012. Thermal comfort models: A review and numerical investigation. Building and Environment 47, 13-22.

De Giuli, V., Zecchin, R., Corain, L., Salmaso, L., 2014. Measured and perceived environmental comfort: field monitoring in an Italian school. Applied ergonomics 45, 1035-1047.

Fanger, P.O., 1970. Thermal comfort. Analysis and applications in environmental engineering. Thermal comfort. Analysis and applications in environmental engineering. Fiala, D., Lomas, K.J., Stohrer, M., 2001. Computer prediction of human thermoregulatory and temperature responses to a wide range of environmental conditions. International Journal of Biometeorology 45, 143-159.

Gagge, A.P., J.A.J., S., Y., N., 1971. An effective temperature scale based on a single model of human physiological temperature response. ASHRAE Transactions 77, $247-$ 262.

Gagge, A.P., Nishi, Y., 2011. Heat exchange between human skin surface and thermal environment. Comprehensive Physiology.

Gordon, R.G., Roemer, R.B., Horvath, S.M., 1976. A mathematical model of the human temperature regulatory system-transient cold exposure response. Biomedical Engineering, IEEE Transactions on, 434-444.

Holopainen, R., Tuomaala, P., Hernandez, P., Häkkinen, T., Piira, K., Piippo, J., 2014. Comfort assessment in the context of sustainable buildings: comparison of simplified and detailed human thermal sensation methods. Building and environment 71, 60-70. Huizenga, C., Hui, Z., Arens, E., 2001. A model of human physiology and comfort for assessing complex thermal environments. Building and Environment 36, 691-699.

ISO-7726, 2001. Ergonomics of the thermal environment. Instruments for measuring physical quantities International Organization for Standardization.

ISO-7730, 2005. Ergonomics of the thermal environment, Analytical determination and interpretation of thermal comfort using calculation of the PMV and PPD indices and local thermal comfort criteria. International Organization for Standardization.

Kobayashi, Y., Tanabe, S.-i., 2013. Development of JOS-2 human thermoregulation model with detailed vascular system. Building and Environment 66, 1-10.

Lomas, K., Fiala, D., Stohrer, M., 2003. First principles modeling of thermal sensation responses in steady-state and transient conditions.

Martin Bland, J., Altman, D., 1986. Statistical methods for assessing agreement between two methods of clinical measurement. The lancet 327, 307-310.

McCullough, E.A., Jones, B.W., Huck, J., 1985. A comprehensive data base for estimating clothing insulation. Ashrae Trans 91, 29-47. 
Munir, A., Takada, S., Matsushita, T., 2009. Re-evaluation of Stolwijk's 25-node human thermal model under thermal-transient conditions: Prediction of skin temperature in low-activity conditions. Building and Environment 44, 1777-1787.

Parsons, K., 2014. Human thermal environments: the effects of hot, moderate, and cold environments on human health, comfort, and performance. Crc Press.

Stolwijk, J., 1971. A mathematical model of physiological temperature regulation in man. National Aeronautics and Space Administration.

Takada, S., Kobayashi, H., Matsushita, T., 2009. Thermal model of human body fitted with individual characteristics of body temperature regulation. Building and Environment 44, 463-470.

Tanabe, S.-i., Kobayashi, K., Nakano, J., Ozeki, Y., Konishi, M., 2002. Evaluation of thermal comfort using combined multi-node thermoregulation $(65 \mathrm{MN})$ and radiation models and computational fluid dynamics (CFD). Energy and Buildings 34, 637-646.

Wan, X., Fan, J., 2008. A transient thermal model of the human body-clothingenvironment system. Journal of Thermal Biology 33, 87-97.

Wang, X., 1994. Thermal comfort and sensation under transient conditions. Department of Energy Technology, Division of Heating and Ventilation, the Royal Institute of Technology.

Werner, J., Webb, P., 1993. A six-cylinder model of human thermoregulation for general use on personal computers. Annals of physiological anthropology 12, 123-123.

$\mathrm{Xu}, \mathrm{X}$., Werner, J., 1997. A dynamic model of the human/clothing/environment-system. Applied human science: journal of physiological anthropology 16, 61-75.

Yang, Y., 2015. Indoor Thermal Response of Human Body in Uniform Environment (Warm Conditions). Chongqing University, Phd. Thesis.

Yang, Y., Yao, R., Li, B., Liu, H., Jiang, L., 2015a. A Method of Evaluating the Accuracy of Human Body Thermoregulation Models. Building and Environment.

Yang, Y., Yao, R., Li, B., Liu, H., Jiang, L., 2015b. A method of evaluating the accuracy of human body thermoregulation models. Building and Environment 87, 1-9.

Yao, T., 2005. Physiology. Fudan University Press, Shanghai.

Yi, L., Fengzhi, L., Yingxi, L., Zhongxuan, L., 2004. An integrated model for simulating interactive thermal processes in human-clothing system. Journal of Thermal Biology 29, 567-575.

Zhang, H., Huizenga, C., Arens, E., Yu, T., 2001. Considering individual physiological differences in a human thermal model. Journal of thermal biology 26, 401-408.

Zhou, X., Lian, Z., Lan, L., 2013. An individualized human thermoregulation model for Chinese adults. Building and environment 70, 257-265.

Zhou, X., Zhang, H., Lian, Z., Zhang, Y., 2014. A model for predicting thermal sensation of Chinese people. Building and Environment 82, 237-246.

Zolfaghari, A., Maerefat, M., 2010. A new simplified thermoregulatory bioheat model for evaluating thermal response of the human body to transient environments. Building and Environment 45, 2068-2076. 